\title{
Neutron Coincidence Counting Studies
}

Jeremy L. Rogers

James H. Ely

Richard T. Kouzes

Azaree T. Lintereur

Edward R. Siciliano

August 2012

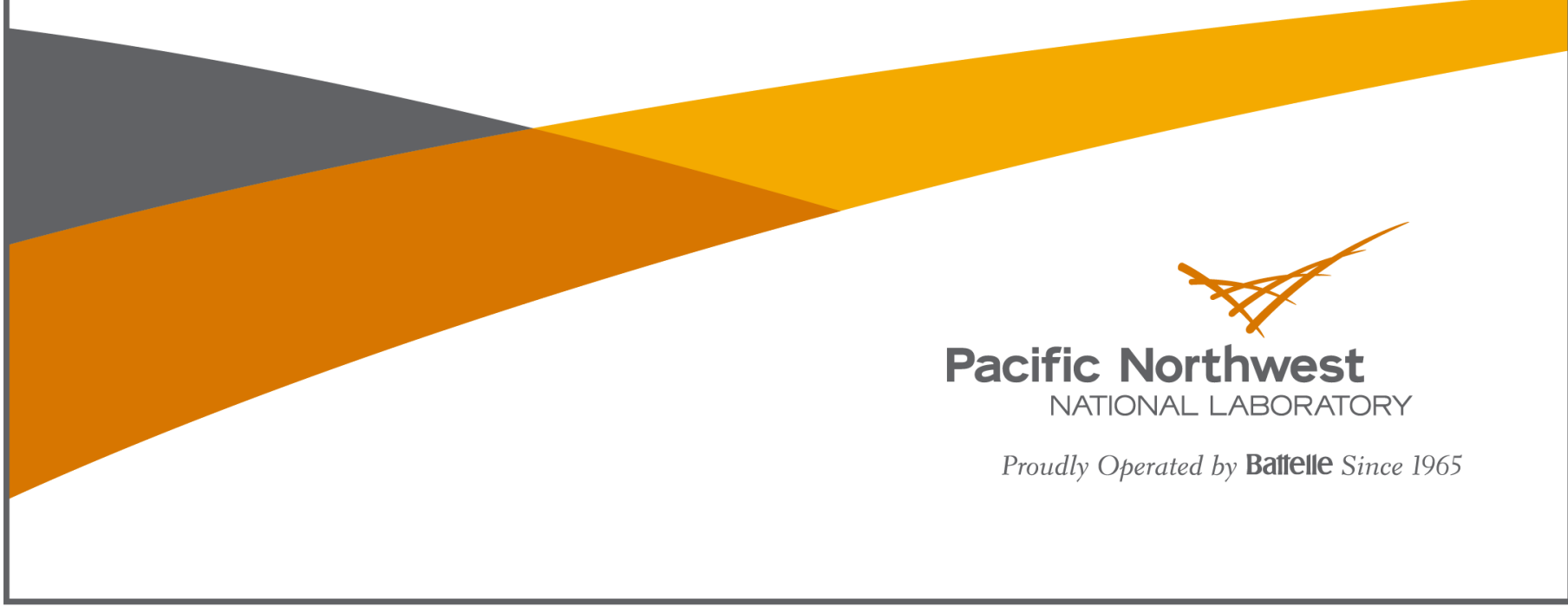




\title{
DISCLAIMER
}

This report was prepared as an account of work sponsored by an agency of the United States Government. Neither the United States Government nor any agency thereof, nor Battelle Memorial Institute, nor any of their employees, makes any warranty, express or implied, or assumes any legal liability or responsibility for the accuracy, completeness, or usefulness of any information, apparatus, product, or process disclosed, or represents that its use would not infringe privately owned rights. Reference herein to any specific commercial product, process, or service by trade name, trademark, manufacturer, or otherwise does not necessarily constitute or imply its endorsement, recommendation, or favoring by the United States Government or any agency thereof, or Battelle Memorial Institute. The views and opinions of authors expressed herein do not necessarily state or reflect those of the United States Government or any agency thereof.

\author{
PACIFIC NORTHWEST NATIONAL LABORATORY \\ operated by \\ BATTELLE \\ for the \\ UNITED STATES DEPARTMENT OF ENERGY \\ under Contract DE-AC05-76RL01830
}

Printed in the United States of America

\section{Available to DOE and DOE contractors from the \\ Office of Scientific and Technical Information, \\ P.O. Box 62, Oak Ridge, TN 37831-0062; \\ ph: (865) 576-8401 \\ fax: (865) 576-5728 \\ email: reports@adonis.osti.gov}

Available to the public from the National Technical Information Service, U.S. Department of Commerce, 5285 Port Royal Rd., Springfield, VA 22161

ph: (800) 553-6847

fax: (703) 605-6900

email: orders@ntis.fedworld.gov

online ordering: http://www.ntis.gov/ordering.htm 


\section{Neutron Coincidence Counting Studies}

Jeremy L. Rogers

James H. Ely

Richard T. Kouzes

Azaree T. Lintereur

Edward R. Siciliano

August 2012

Pacific Northwest National Laboratory

Richland, Washington 99352 


\section{Executive Summary}

The Department of Energy Office of Nuclear Safeguards and Security (NA-241) is supporting the project Coincidence Counting With Boron-Based Alternative Neutron Detection Technology at Pacific Northwest National Laboratory (PNNL) for the development of an alternative neutron coincidence counter. The goal of this project is to design, build and demonstrate an alternative system based upon ${ }^{10} \mathrm{~B}$-lined proportional tubes in a configuration typical for ${ }^{3} \mathrm{He}$-based coincidence counter applications.

This report provides results of various studies related to this project performed by a summer intern supported by the Next Generation Safeguards Initiative program.

The efficiency comparison for measured and simulated responses of a ${ }^{10} \mathrm{~B}$-lined proportional counter and a ${ }^{3} \mathrm{He}$ proportional counter in a close, symmetrical geometry are presented. The measurement geometry was modeled in MCNPX to validate the methods used for simulating the response of both the ${ }^{3} \mathrm{He}$ and ${ }^{10} \mathrm{~B}$-lined tubes. Using total count efficiency as the measure of comparison, the experimental efficiencies of the ${ }^{3} \mathrm{He}$ counter to the ${ }^{10} \mathrm{~B}$-lined tube were determined to be 6.39:1. The MCNPX models agree within $1 \%$ with the ${ }^{3} \mathrm{He}$ tube measurements and within $3 \%$ for the ${ }^{10} \mathrm{~B}$-lined tubes when a $0.75-\mu \mathrm{m}$ boron-metal lining is used. 


\section{Acronyms and Abbreviations}

\begin{tabular}{ll} 
ABUNCL & Alternative Boron-based Uranium Neutron Coincidence Collar \\
AmLi & Americium-lithium neutron source \\
BWR & Boiling water reactor \\
DOE & U.S. Department of Energy \\
$\varepsilon$ & Detection efficiency \\
FWHM & Full Width at Half Maximum \\
GE & General Electric \\
GEB & Gaussian Energy Broadening \\
HDPE & High Density Polyethylene \\
IAEA & International Atomic Energy Agency \\
LEC & Low-Energy Cutoff \\
MCA & Multi-Channel Analyzer \\
MOX & Mixed Oxide fuel \\
NIM & Nuclear Instrument Module \\
PHL & Pulse-Height Light \\
PNNL & Pacific Northwest National Laboratory \\
Pu & Plutonium \\
PWR & Pressurized water reactor \\
U & Die-away time \\
UNCL & Uranium \\
\hline & Pranium Neutron Coincidence Collar \\
\hline &
\end{tabular}




\section{Contents}

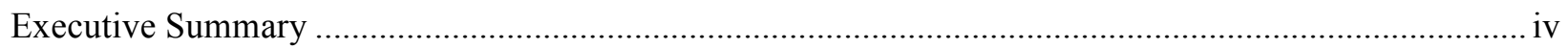

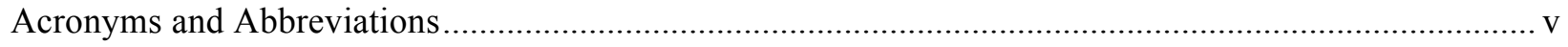

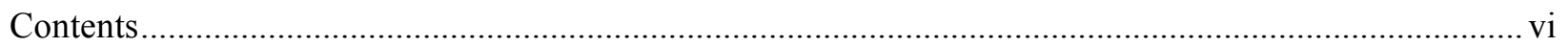

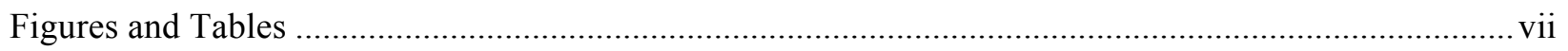

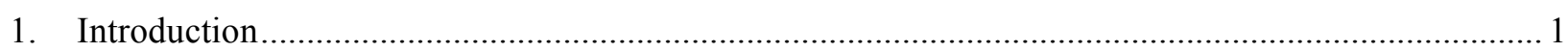

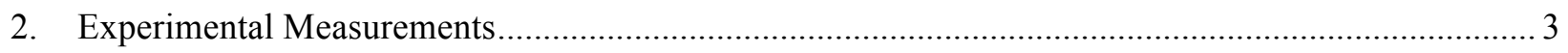

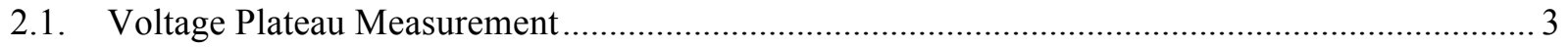

2.2. Boron-10 Shaping Time Measurement ……......................................................................... 4

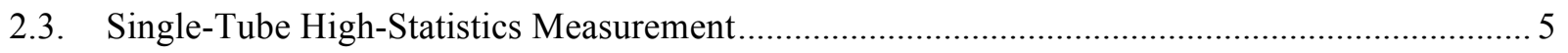

2.4. Helium-3 Single-Tube High-Statistics Measurement .......................................................... 7

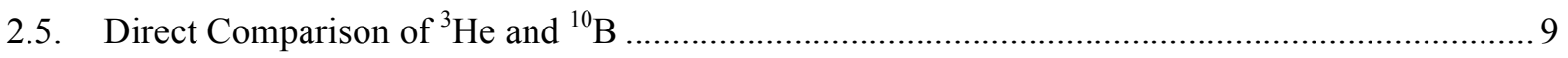

2.6. Re-measurement of ${ }^{10} \mathrm{~B}$ Single-tube versus Distance ............................................................. 10

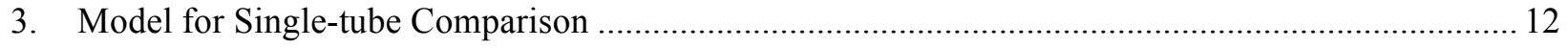

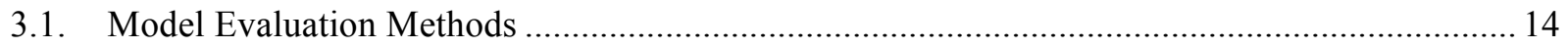

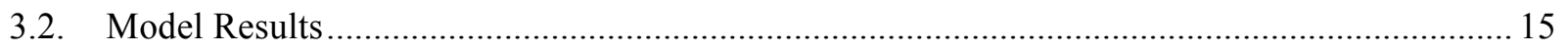

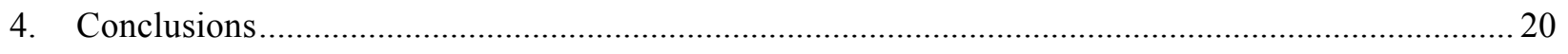

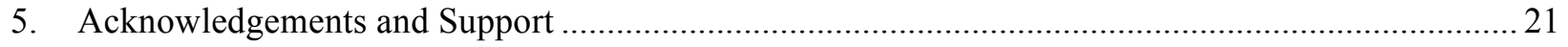

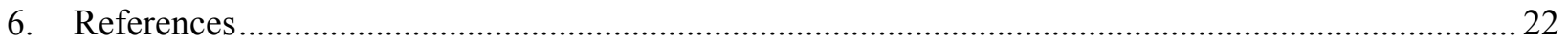




\section{Figures and Tables}

\section{Figures}

Figure 1.1. An UNCL-II (active configuration) coincidence counter, with the source-containing front block in the foreground [Croft 2011].

Figure 2.1. Comparison of the applied high voltage profiles for two ${ }^{10} \mathrm{~B}$-lined proportional counters, using

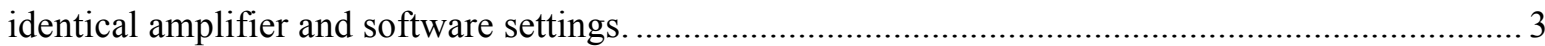

Figure 2.2. Effect of amplifier shaping constant on ${ }^{10} \mathrm{~B}$-lined proportional counter pulse height spectra.... 4

Figure 2.3. Moderator configuration for the ${ }^{3} \mathrm{He}$ (top) and ${ }^{10} \mathrm{~B}$ (bottom) single-tube measurements.......... 5

Figure 2.4. Pulse-height spectrum from a $24-\mathrm{hr}$ spectral acquisition in a ${ }^{10} \mathrm{~B}$-lined proportional counter. .. 7

Figure 2.5. Pulse-height spectrum from a $24-\mathrm{hr}$ spectral acquisition in a ${ }^{3} \mathrm{He}$ proportional counter operated

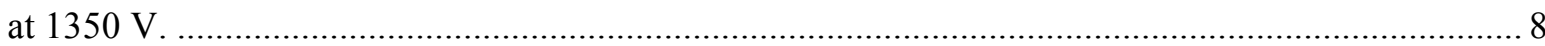

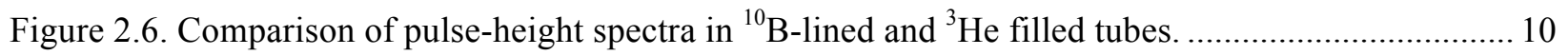

Figure 2.7. Moderated ${ }^{10} \mathrm{~B}$-lined tube (right) and moderated ${ }^{252} \mathrm{C}$ f source on tripod (left)...................... 11

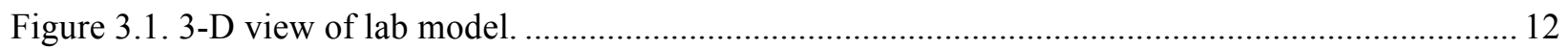

Figure 3.2. Top down view of the moderator arrangement $\left[{ }^{3} \mathrm{He}\right.$ tube is red, ${ }^{10} \mathrm{~B}$-lined tube is green]. ...... 13

Figure 3.3. Side view of the moderator arrangement, including the source (center) and several nearby

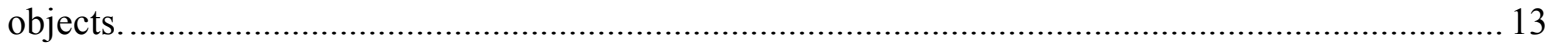

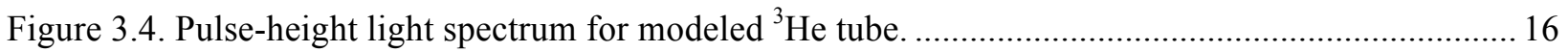

Figure 3.5. Comparison of measured pulse height spectra for ${ }^{10} \mathrm{~B}$-lined proportional counter with model pulse height spectra using various ${ }^{10} \mathrm{~B}$ lining thicknesses and compositions. ................................ 18

Figure 3.6. Effect of boron lining thickness on n-capture reactions, count efficiency, and die-away time in individual ${ }^{10} \mathrm{~B}$-lined detector system.

\section{Tables}

Table 2.1. Measured efficiencies for the ${ }^{3} \mathrm{He}$ and ${ }^{10} \mathrm{~B}$-lined tubes over 24-hour measurement periods. ...... 9 Table 2.2. Results of response of individual, moderated ${ }^{10} \mathrm{~B}$-lined tube to moderated ${ }^{252} \mathrm{Cf}$ source.......... 11

Table 3.1. Percent difference between model and measurements for individual ${ }^{3} \mathrm{He}$ tube....................... 16

Table 3.2. Percent differences between model and measurements for individual ${ }^{10} \mathrm{~B}$-lined tubes. ........... 17 


\section{Introduction}

The demand for ${ }^{3} \mathrm{He}$ gas has far outstripped the supply in recent years, causing a drastic increase in ${ }^{3} \mathrm{He}$ prices. The search for technological alternatives to ${ }^{3} \mathrm{He}$ is a major research area in nuclear security and safeguards [Kouzes 2010; Menlove 2011].

Coincidence Counting With Boron-Based Alternative Neutron Detection Technology is a Pacific Northwest National Laboratory (PNNL) project supported by the Department of Energy Office of Nuclear Safeguards and Security (NA-241) for developing an alternative-based neutron coincidence counter [Kouzes 2012].

Coincidence counting is a high-precision technique used to measure the mass of plutonium $(\mathrm{Pu})$ or uranium $(\mathrm{U})$ in samples for safeguards applications. Neutrons can be produced through spontaneous fission, induced fission, $(\alpha, n)$ reactions, and cosmic ray events. Neutrons produced from fission or cosmic ray events, which both emit multiple neutrons simultaneously, are correlated in time. Coincidence counters use instruments called shift registers to detect time correlated neutrons in order to separate fission events from the background, which is comprised of uncorrelated neutrons. This background is produced by neutrons that are created at random moments in time, such as those emitted by the $(\alpha, n)$ sources used in active interrogation systems. Since neutrons from thermal fission and spontaneous fission are emitted isotropically, coincidence counters use large banks of multiple neutron detectors in order to approach $4 \pi$ measurement geometries [Kouzes 2012; PANDA 1991].

Coincidence counters falls into one of two main categories, passive and active. Passive coincidence counters are used for both fresh and spent Pu-based fuels, and fuel processing, where plutonium accountancy is the objective. Active coincidence counting, where an external neutron source is used to induce fission in the sample being assayed, is used for U-based fresh fuels [Kouzes 2012].

The Uranium Neutron Coincidence Collar (UNCL) is used by the International Atomic Energy Agency (IAEA) for verification of the mass of ${ }^{235} U$ in low-enriched $U$ fuel assemblies [Menlove 1981; Menlove 1990]. It consists of either three or four banks of detectors surrounding a central cavity where the fuel assembly is placed during measurements. The original UNCL (referred to in this report as the "UNCL-I") received an update in design (known as the UNCL-II) in 1989 to reduce measurement times and incorporate new electronics, though the UNCL-I is still used in some applications [Menlove 1990]. Since pressurized water reactor (PWR) and boiling water reactor (BWR) fuel assemblies have different cross-sections, both the UNCL-I and UNCL-II each use different geometries and numbers of tubes for measuring PWR and BWR fuel assemblies. Additionally, each of these four configurations can be used in either an active mode for measurement of uranium in fresh fuel, or a passive mode for measurement of plutonium in mixed oxide (MOX) fuels. In the active mode, the front side of the counters use a moderating block with a slot for an external neutron source (usually an americium-lithium [AmLi] $(\alpha, n)$ source). In the passive mode, the front of the counters is a fourth bank of detectors. In total, the suite of UNCL counters thus has eight different configurations: UNCL-I or UNCL-II, PWR or BWR, active or passive [Siciliano 2012b]. An example of an UNCL-II is shown in Figure 1.1, taken from Croft [2011]. 
The current generation of coincidence counters has been designed with ${ }^{3} \mathrm{He}$ proportional counters as the detection elements. Sections 2-3 of this report describe the experimental measurements and MCNPX validation modeling of single ${ }^{10} \mathrm{~B}$ and ${ }^{3} \mathrm{He}$ proportional counters. A future report will detail the simulation results of a full UNCL system using ${ }^{10} \mathrm{~B}$-lined proportional counters as the detection elements in place of ${ }^{3} \mathrm{He}$ proportional counters.

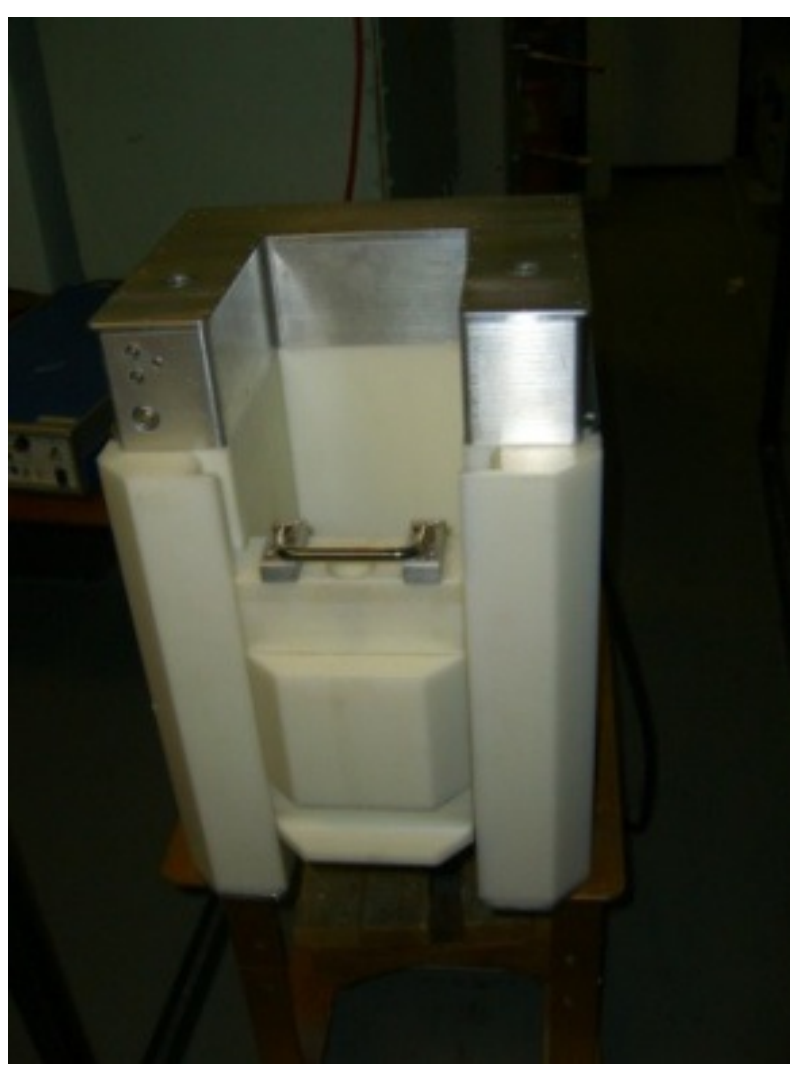

Figure 1.1. An UNCL-II (active configuration) coincidence counter, with the source-containing front block in the foreground [Croft 2011]. 


\section{Experimental Measurements}

Measurements were made with two single-tube neutron detection systems: one ${ }^{10} \mathrm{~B}$-lined proportional counter and one ${ }^{3} \mathrm{He}$-filled proportional counter. These measurements were made to determine the effect of single tubes in a moderator configurations similar to that used in the UNCL designs. The ${ }^{10} \mathrm{~B}$-lined tubes used for these measurements were provided by General Electric (GE) Reuter-Stokes, tube model number RS-B1-0824-101. These tube has an outside diameter of $2.54 \mathrm{~cm}$ ( 1 inch) and an active height of $71.1-\mathrm{cm}(28-i n c h)$ long with a $61.0-\mathrm{cm}(24-$ inch). For additional details on the construction of these tubes, a schematic drawing can be seen in a previous report [Kouzes 2012]. In the following discussion, this tube will be referred to simply as "the ${ }^{10} \mathrm{~B}$-lined tube."

\subsection{Voltage Plateau Measurement}

The inside surface of the GE Reuter-Stokes ${ }^{10} \mathrm{~B}$-lined tube is coated with a very thin layer of boron enriched to $\sim 92 \%{ }^{10} \mathrm{~B}$ content. The tubes are filled with a mixture of argon and carbon dioxide [GE Reuter-Stokes 2005]. The operating voltage recommended by GE Reuter-Stokes for this tube is $760 \mathrm{~V}$. To verify that this voltage setting was in the proportional operating region, the applied high voltage setting was altered and the effects were observed in a series of 120 -s counts. The proportional region is characterized by a "plateau" region on a plot of count rate versus applied voltage. In the proportional region, the count rate and efficiency are only slowly increasing as a function of applied high voltage. Figure 2.1 shows that the optimal operating voltage for the ${ }^{10} \mathrm{~B}$-lined tube used in this study (Tube 1) is in the range of $730-770 \mathrm{~V}$.

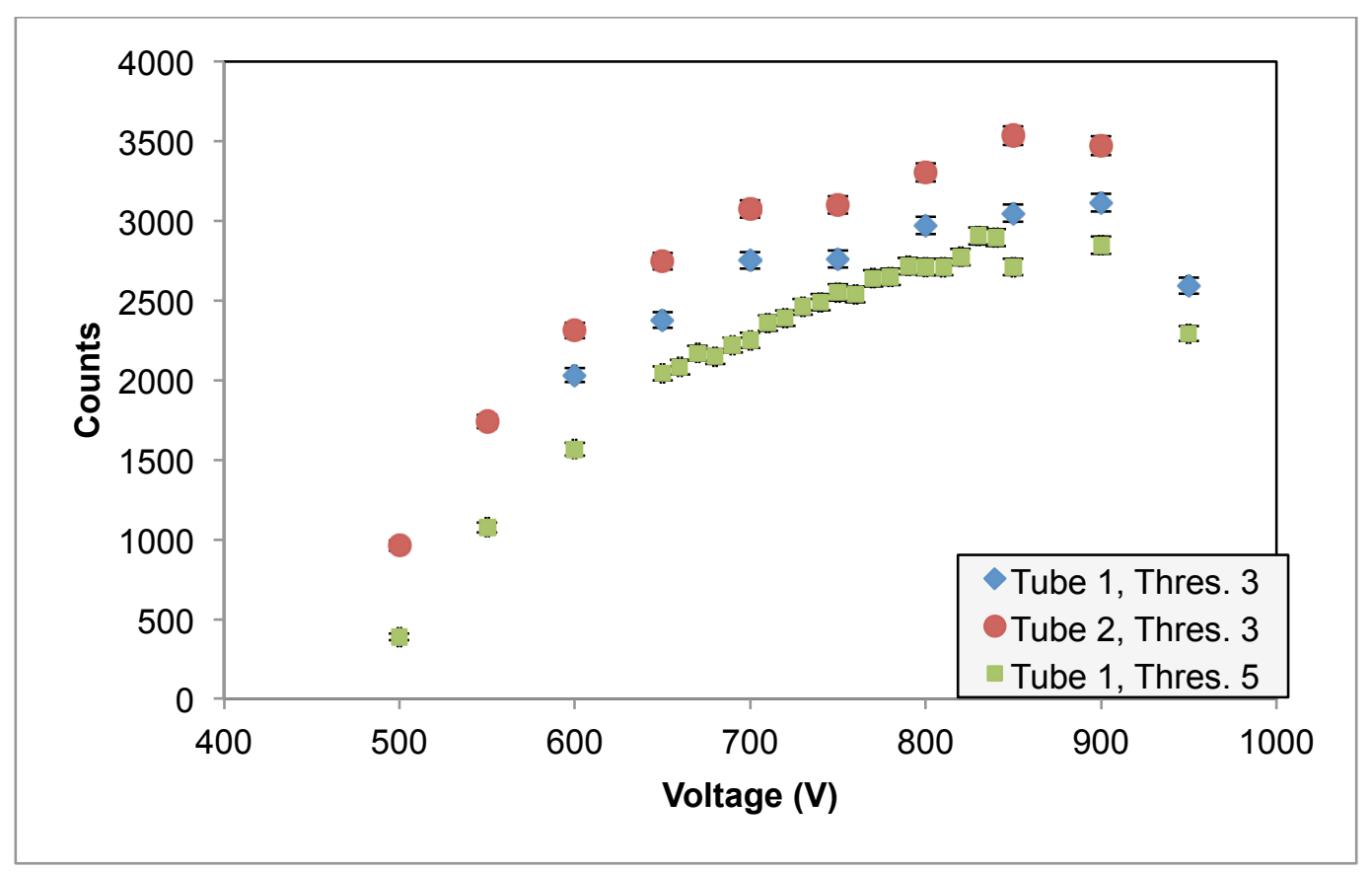

Figure 2.1. Comparison of the applied high voltage profiles for two ${ }^{10} \mathrm{~B}$-lined proportional counters, using identical amplifier and software settings. 
A second GE Reuter-Stokes ${ }^{10} \mathrm{~B}$ tube (Tube 2) was also tested to verify the results. The low level thresholds were applied to reduce the noise in the low energy portion of the spectrum. The number of counts tails off at higher voltages because the increased gain began to push the highenergy counts off the 512-channel spectrum. Thus, not all of the signal pulses were counted at the higher voltages (above $\sim 900 \mathrm{~V}$ ).

\subsection{Boron-10 Shaping Time Measurement}

The ORTEC 673 Spectroscopy Amplifier and Gated Integrator has a shaping constant setting that alters the integration time of the signal pulse, and can be impacted by count rate. Longer shaping times are often used to provide better energy resolution at low counting rates [ORTEC 2010]. Pulse height spectra collected using shaping time settings of $0.25 \mu \mathrm{s}, 0.5 \mu \mathrm{s}$, and $1 \mu \mathrm{s}$ are shown in Figure 2.2. Each spectrum was acquired over $600 \mathrm{~s}$, except for the $0.25 \mu$ s spectrum, which was acquired over $300 \mathrm{~s}$ and is normalized for comparison. From this comparison, the 0.5 $\mu \mathrm{s}$ or $1 \mu \mathrm{s}$ shaping times produce more consistent data for the ${ }^{10} \mathrm{~B}$-lined proportional counter. The $1 \mu$ s setting was used as the shaping time for the remainder of the measurements included in this report.

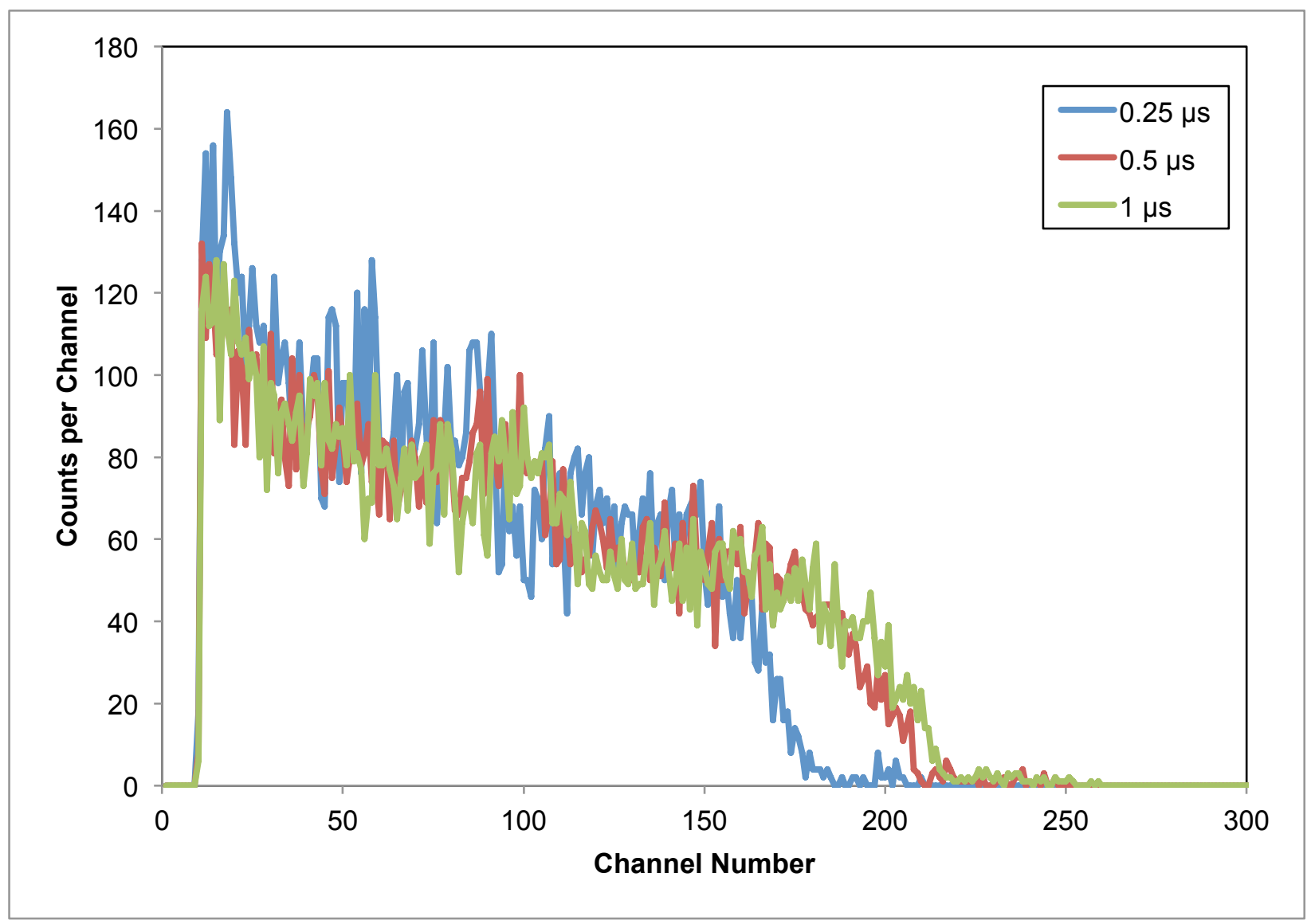

Figure 2.2. Effect of amplifier shaping constant on ${ }^{10} \mathrm{~B}$-lined proportional counter pulse height spectra. 


\subsection{Single-Tube High-Statistics Measurement}

A 24-hour measurement was acquired with a single GE Reuter Stokes ${ }^{10} \mathrm{~B}$-lined tube to get high statistics (greater than $0.1 \%$ accuracy) for its response to a moderated ${ }^{252} \mathrm{Cf}$ source. The activity of this source was $1.93 \mu \mathrm{Ci}\left(3.58 \mathrm{ng}, 8.2 \times 10^{3}\right.$ neutrons s$\left.{ }^{-1}\right)$ on date of measurement, June 12 , 2012. The ${ }^{10} \mathrm{~B}$-lined tube was placed in the middle slot of a polyethylene moderator block, which was placed in contact with the source holder (which is about two inches from the actual source). A small foam spacer was added to stabilize the tube because the openings in the moderator were designed for 5.08-cm (2-inch) diameter tubes. The other two tube slots were not filled with tubes. The ${ }^{10} \mathrm{~B}$-lined tube is pictured in the bottom moderator block in Figure 2.3. Three identical moderator blocks were arranged around the block containing the ${ }^{10} \mathrm{~B}$-lined tube. The polyethylene block directly opposite the ${ }^{10} \mathrm{~B}$-lined tube contained a ${ }^{3} \mathrm{He}$ tube (described below) in its middle slot. This polyethylene block was also placed in contact with the source (seen as the round polyethylene object in the center of the figure). The two adjacent blocks each included identical ${ }^{3} \mathrm{He}$-filled detectors in their middle tube slots, but these detectors were only used for symmetry of the moderator arrangement and were not measured.

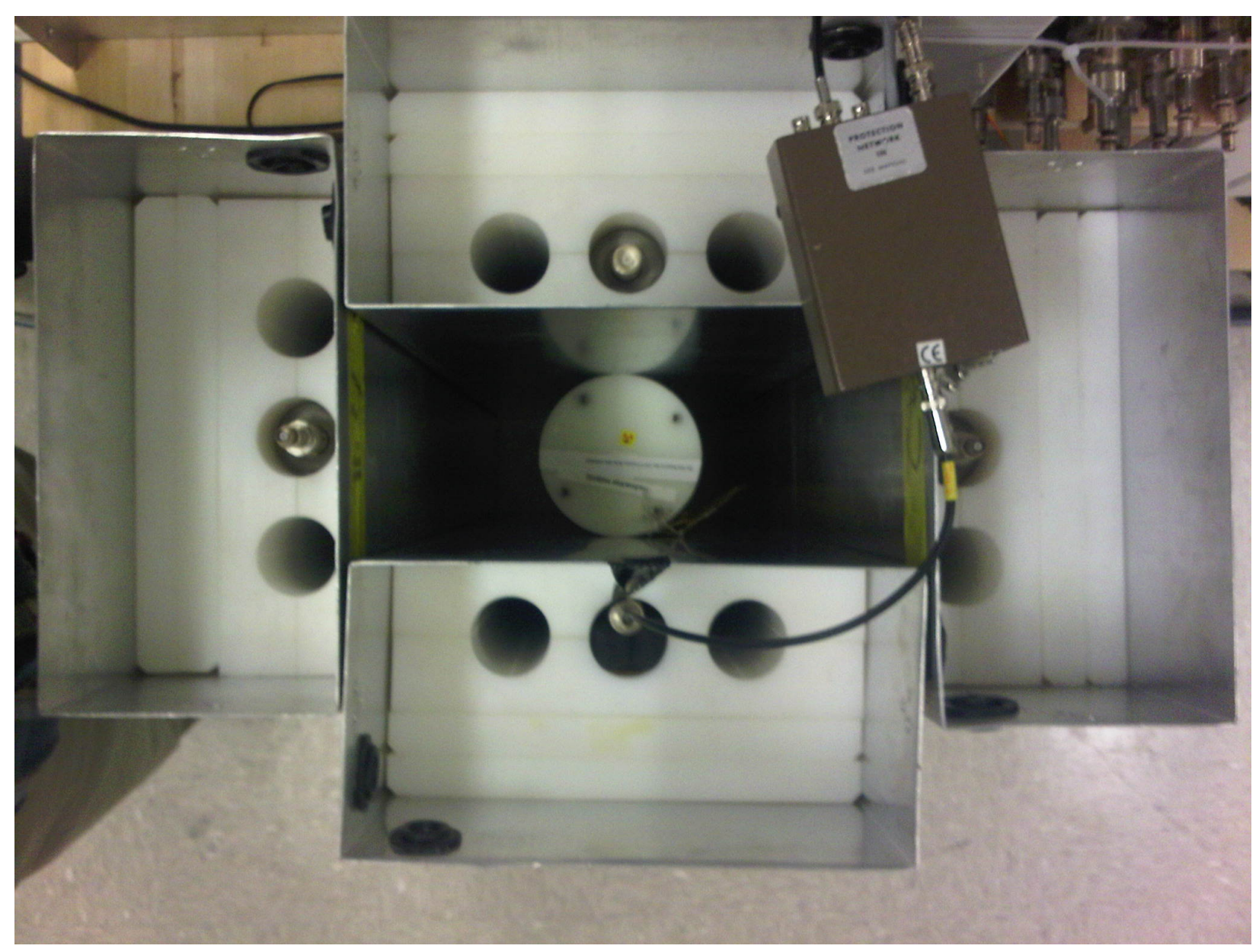

Figure 2.3. Moderator configuration for the ${ }^{3} \mathrm{He}$ (top) and ${ }^{10} \mathrm{~B}$ (bottom) single-tube measurements. 
The moderator geometry was used to maintain a consistent measurement configuration and to reduce the effect of background neutrons in the laboratory in Building 3420 at PNNL where the measurements were acquired. The response of the ${ }^{3} \mathrm{He}$ and ${ }^{10} \mathrm{~B}$ tubes were measured in this configuration, using the same electronics, in order to provide a direct, geometry- and background-independent comparison. An ORTEC Model 556 High Voltage Power Supply and an ORTEC 673 Spectroscopy Amplifier and Gated Integrator were placed inside a Canberra 2100 Nuclear Instrument Module (NIM) bin, and an ORTEC 142AH preamplifier (pictured in Figure 2.3) was used to route the signal to the NIM bin. An AMPTEK Model 8000A Pocket Multi-Channel Analyzer (MCA) was used to place the detection signals into channels based on the energy pulses recorded. The amplifier gain was set to $\mathrm{x} 50$, and the software low-energy cutoff (LEC) on the Pocket MCA was set to channel 3.

Boron-based thermal neutron detection uses the ${ }^{10} \mathrm{~B}(\mathrm{n}, \alpha)$ reaction, which can be written as:

$$
{ }_{5}^{10} \mathrm{~B}+{ }_{0}^{1} \mathrm{n} \rightarrow\left\{\begin{array}{lr}
{ }_{3}^{7} \mathrm{Li}+{ }_{2}^{4} \mathrm{He} & 6 \%, 2.792 \mathrm{MeV} \text { (ground state) } \\
{ }_{3}^{7} \mathrm{Li}^{*}+{ }_{2}^{4} \mathrm{He} & 94 \%, 2.310 \mathrm{MeV} \text { (excited state) }
\end{array}\right.
$$

The kinetic energy imparted to the products in the more probable reaction is $\mathrm{E}_{\mathrm{Li}}=0.840 \mathrm{MeV}$ and $\mathrm{E}_{\mathrm{He}}=1.470 \mathrm{MeV}$. When the ${ }^{7} \mathrm{Li}$ nucleus is emitted in the ground state, however, the kinetic energy of the products is $\mathrm{E}_{\mathrm{Li}}=1.015 \mathrm{MeV}$ and $\mathrm{E}_{\mathrm{He}}=1.777 \mathrm{MeV}$. The thermal neutron capture cross-section of ${ }^{10} \mathrm{~B}$ is 3840 barns and like ${ }^{3} \mathrm{He}$, the ${ }^{10} \mathrm{~B}$ neutron capture cross-section decreases proportionally with $1 / v$, where $v$ is the neutron speed [Knoll 2000].

The pulse-height spectrum from the ${ }^{10} \mathrm{~B}$-lined proportional counter is shown in Figure 2.4. The double-plateau shape is characteristic of detectors where the neutron capture interactions occur in the detector lining and produce two charged particle products. Since the detector lining is thicker than the mean free path of the charged particles, the reaction products that escape into the proportional gas can deposit energy ranging from zero to their full Q-value allowed kinetic energies. The drop-off in signal near channel 200 corresponds to the alpha particle's maximum deposited kinetic energy of $1.470 \mathrm{MeV}$, while the drop off near channel 110 corresponds to the ${ }^{7} \mathrm{Li}$ ion's maximum kinetic energy of $0.840 \mathrm{MeV}$. Because the distribution of alpha particle energies extends to zero, the higher count rate in the ${ }^{7} \mathrm{Li}$ region results from the summing of the two plateaus.

Although both the ${ }^{7} \mathrm{Li}$ and alpha drop-offs show a blurring from their crisp, kinematic (stepfunction) values, the drop-off at the end of the ${ }^{7} \mathrm{Li}$ region is steeper than that at the end of the alpha region. That difference is characteristic of the wall effect on the alpha ions, where because of its longer mean free path in the gas, the alpha ions entering the gas with higher values of energy only deposit some of their energy before striking an opposing wall. This wall effect exists in both cylindrical and parallel plate geometries, but is much more pronounced for small diameter cylindrical geometries with low gas pressures (such as the one third of an atmosphere in the tubes tested). These details of the shape of pulse height spectra in ${ }^{10} \mathrm{~B}$-lined tubes may provide some useful diagnostic information on the optimal composition and thickness of the lining material [Siciliano 2012]. 
Finally note that a low count-rate region exists above channel $\sim 220$. This region appears in long ${ }^{10} \mathrm{~B}$-lined data acquisitions because $6 \%$ of the time, the neutron capture reaction produces a ${ }^{7} \mathrm{Li}$ particle in its ground state instead of in an excited state. For this low-probability branch of the reaction, the reaction products have $\sim 482 \mathrm{keV}$ more kinetic energy to share between them $(2.792$ $\mathrm{MeV}$ instead of $2.310 \mathrm{MeV}$ ). While the direct evidence of the ${ }^{7} \mathrm{Li}$ ion is lost in the statistical variations near the intersection of the two plateaus, the higher-energy alpha particle is apparent in high statistics ${ }^{10} \mathrm{~B}$-lined detector measurements.

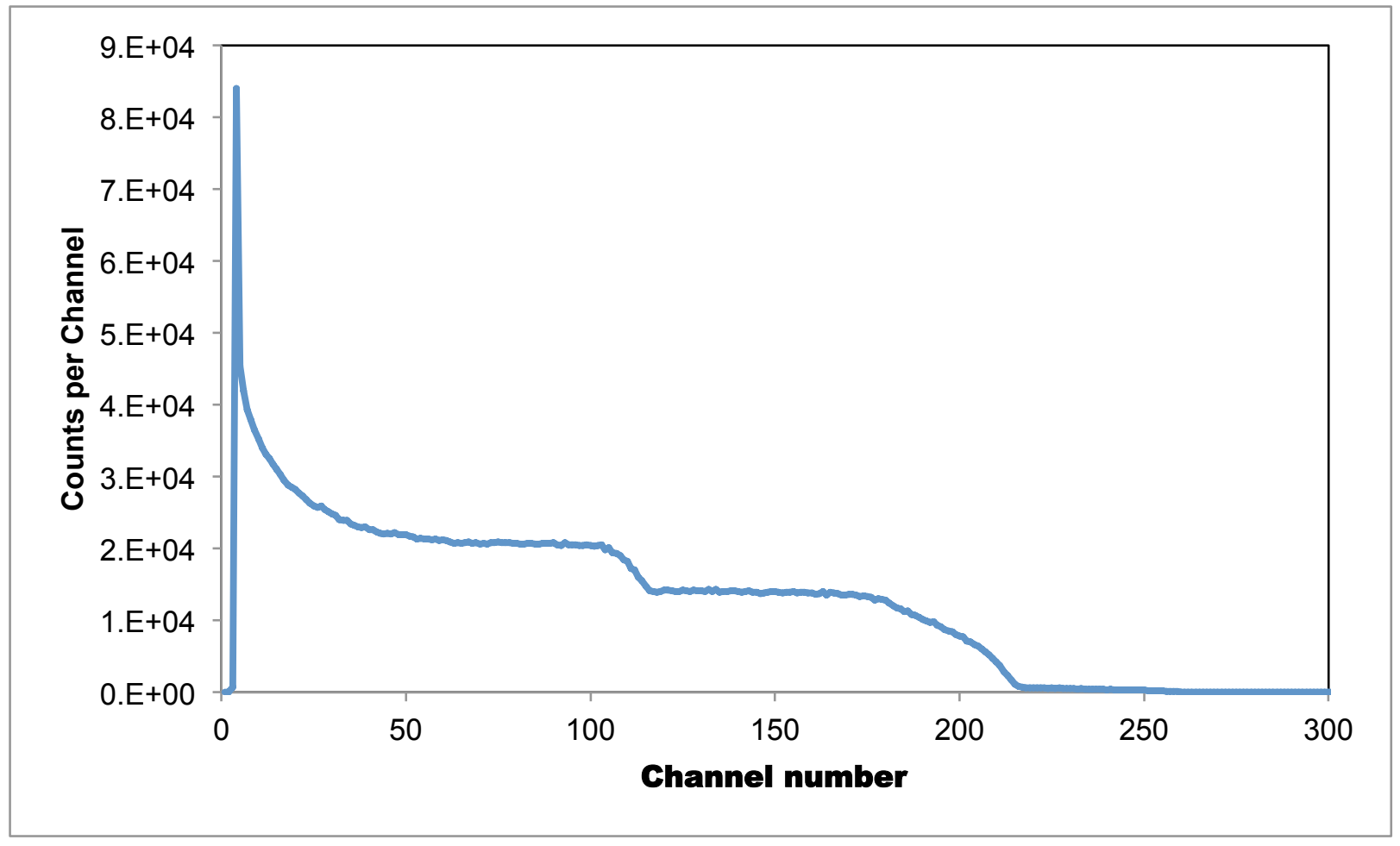

Figure 2.4. Pulse-height spectrum from a $24-h r$ spectral acquisition in a ${ }^{10} \mathrm{~B}$-lined proportional counter.

\subsection{Helium-3 Single-Tube High-Statistics Measurement}

A single ${ }^{3} \mathrm{He}$-filled proportional counter was measured for its response to the same moderated ${ }^{252} \mathrm{Cf}$ source described in Section 2.3. The dimensions of the tube were $5.08-\mathrm{cm}(2.0-\mathrm{inch})$ in diameter and 91.4-cm (36.0-inch) long, with an 86.4-cm (34.0-inch) active length. The tubes were filled with ${ }^{3} \mathrm{He}$ at a pressure of 4 -atmosphere (4.05 bar).

The detector electronics used for the 24 -hour ${ }^{3} \mathrm{He}$ tube measurement were identical to those used for the 24-hour ${ }^{10} \mathrm{~B}$-lined tube measurement, though different voltage and amplifier gain settings were used. For this measurement, the ${ }^{252} \mathrm{Cf}$ source had an activity of $1.94 \mu \mathrm{Ci}\left(3.58 \mathrm{ng}, 8.2 \times 10^{3}\right.$ $\mathrm{n} \mathrm{s}^{-1}$ ) on the date of the measurement, June 11,2012. The optimal operating voltage for GE Reuter-Stokes ${ }^{3} \mathrm{He}$ detectors (model RS-P4-1634-204) was determined by Switzer et al. [Switzer 2003] to be between $1150 \mathrm{~V}$ and $1350 \mathrm{~V}$. The ${ }^{3} \mathrm{He}$ neutron detector in this experiment was 
operated at $1350 \mathrm{~V}$. The amplifier gain was set to $\mathrm{x} 100$, and a shaping time of $3 \mu \mathrm{s}$ was used. As with the ${ }^{10} \mathrm{~B}$-lined measurement, the software LEC was set to channel 3.

The ${ }^{3} \mathrm{He}$ neutron capture reaction is

$$
{ }_{2}^{3} \mathrm{He}+{ }_{0}^{1} \mathrm{n} \rightarrow{ }_{1}^{3} \mathrm{H}+{ }_{1}^{1} \mathrm{p} \quad 0.764 \mathrm{MeV}
$$

As with the boron-capture reaction, the energy of the thermal neutron is negligible compared to the reaction Q-value, and the products are constrained to be emitted in opposite directions in the lab frame, with the proton carrying $0.573 \mathrm{MeV}$ and the triton carrying $0.191 \mathrm{MeV}$ of kinetic energy.

The pulse-height spectrum from the 24-hour measurement is shown in Figure 2.5. The fullenergy (Q-value) peak at channel 185 is visible because the charged reaction particles are emitted in the same material that generates the signal, i.e., the proportional gas. Unlike the ${ }^{10} \mathrm{~B}-$ lined tubes, the wall effect now gives rise to a low-energy tail below the full-energy peak, and kinetic energy values now bound the lower ends of the spectrum. In this lower region of energy, the neutron capture interaction occurs near the detector wall, and either the proton or triton enter the detector wall before depositing their full energy in the proportional gas [Knoll 2000]. The "shoulder" at channel 165 appears when the triton escapes before depositing its $0.191 \mathrm{MeV}$ of kinetic energy. The sharp drop at channel 43 represents the proton escaping into the detector wall while the triton deposits its energy in the proportional gas.

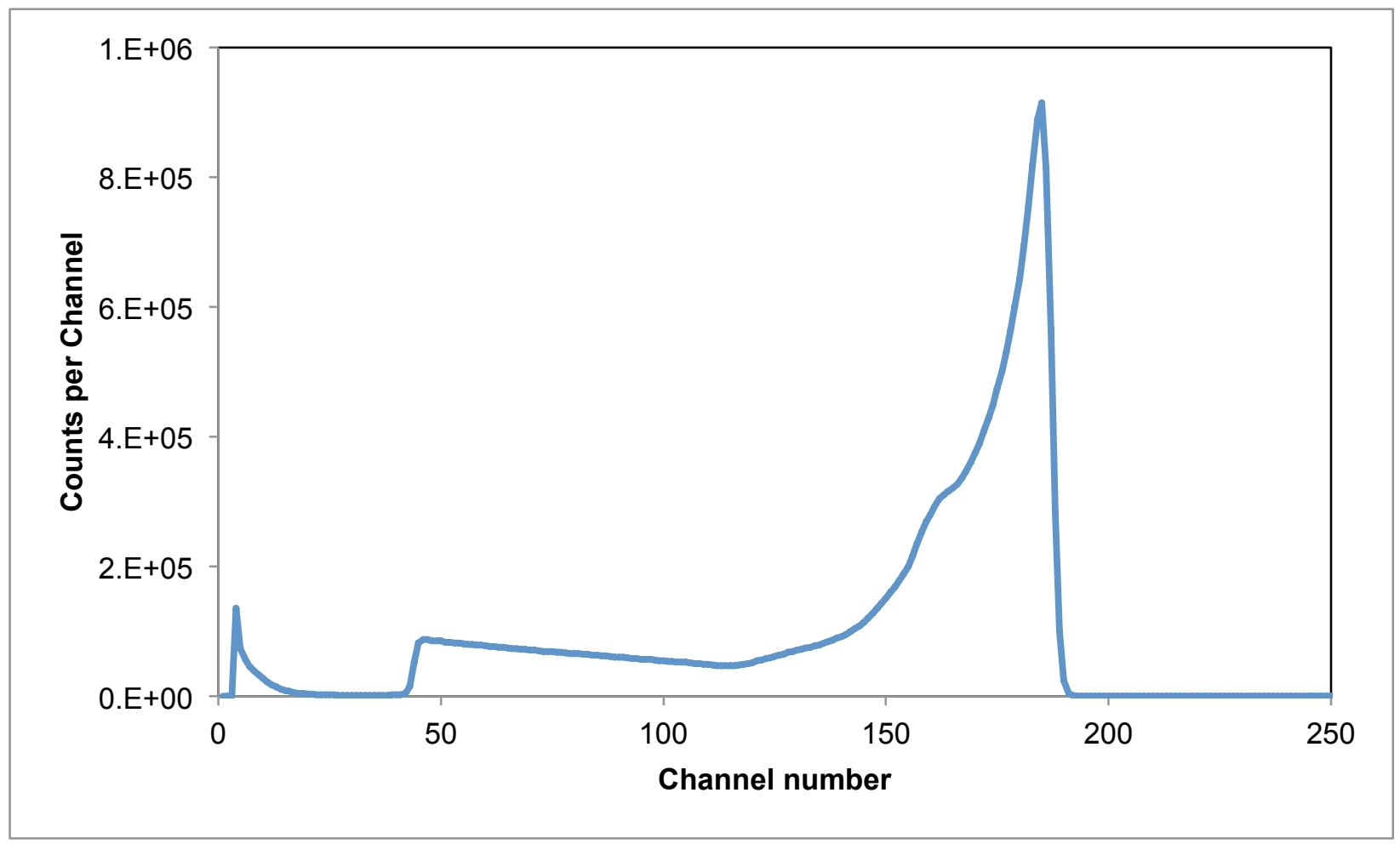

Figure 2.5. Pulse-height spectrum from a $24-\mathrm{hr}$ spectral acquisition in a ${ }^{3} \mathrm{He}$ proportional counter operated at $1350 \mathrm{~V}$. 


\subsection{Direct Comparison of ${ }^{3} \mathrm{He}$ and ${ }^{10} \mathrm{~B}$}

The ${ }^{10} \mathrm{~B}$-lined tube recorded $3.856(2) \times 10^{6}$ total counts, while the ${ }^{3} \mathrm{He}$ tube recorded $2.4684(5) \times 10^{7}$ total counts, over a 24-hour span (background was negligible). Assuming that the ${ }^{252} \mathrm{Cf}$ source strength remained constant throughout each measurement, the absolute efficiency of each detector was recorded as $3.47 \%$ for the ${ }^{3} \mathrm{He}$ tube and $0.54 \%$ for the ${ }^{10} \mathrm{~B}$-lined tube. The efficiency ratio for these two detectors is thus 6.39:1. This difference is due to several factors: ${ }^{3} \mathrm{He}$ 's larger neutron capture cross section, the larger active volume and gas pressure of the ${ }^{3} \mathrm{He}$ tube, and the capture of reaction products in the boron lining without production of a detectable signal.

Table 2.1. Measured efficiencies for the ${ }^{3} \mathrm{He}$ and ${ }^{10} \mathrm{~B}$-lined tubes over 24 -hour measurement periods.

\begin{tabular}{|c|c|c|c|c|c|c|}
\hline Tube & Time (s) & $\begin{array}{c}\text { Strength } \\
\left(\mathbf{n ~ s}^{-1}\right)\end{array}$ & $\begin{array}{c}\text { Total } \\
\text { Neutrons }\end{array}$ & $\begin{array}{c}\text { Total } \\
\text { Counts }\end{array}$ & $\begin{array}{c}\text { Counts } \\
\left(\mathbf{s}^{-1}\right)\end{array}$ & $\begin{array}{c}\text { Efficiency } \\
(\text { counts n }\end{array}$ \\
\hline${ }^{-1} \mathrm{He}$ & 86400 & 8244.2 & $7.123 \times 10^{8}$ & 24684317 & 285.70 & $3.47 \%$ \\
\hline${ }^{10} \mathrm{~B}$ & 86400 & 8238.0 & $7.118 \times 10^{8}$ & 3859631 & 44.67 & $0.54 \%$ \\
\hline
\end{tabular}

The pulse-height spectra of the two different tubes are compared directly in Figure 2.6 using a logarithmic scale for the ordinate. Note that different energy calibration factors have been used to account for the different settings used for applied voltage and amplifier gain. The ${ }^{3} \mathrm{He}$ tube spectrum was calibrated to the $0.764 \mathrm{MeV}$ full-energy peak, and the ${ }^{10} \mathrm{~B}$-lined tube was calibrated to the $1.470 \mathrm{MeV}$ full-energy step of the alpha particle emitted in the excited-state interaction. The broadening of the full-energy region from the wall effect is evident in the response of both tubes. The counts above $0.764 \mathrm{MeV}$ for the ${ }^{3} \mathrm{He}$ tube are due mostly to pileup. 


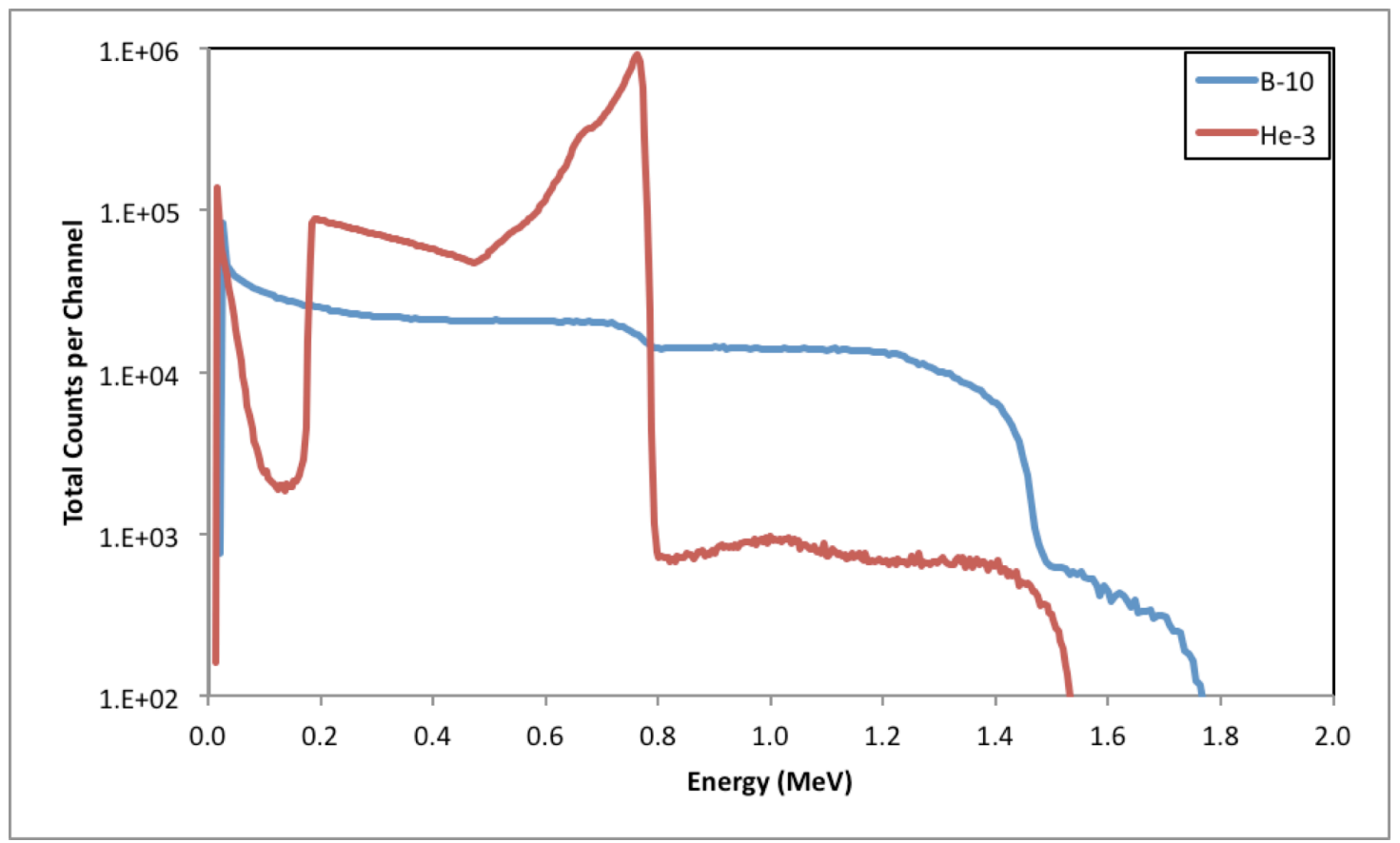

Figure 2.6. Comparison of pulse-height spectra in ${ }^{10} \mathrm{~B}$-lined and ${ }^{3} \mathrm{He}$ filled tubes.

\subsection{Re-measurement of ${ }^{10} \mathrm{~B}$ Single-tube versus Distance}

Previous work at PNNL focused on MCNPX model validation of the response of a single ${ }^{10} \mathrm{~B}$ lined tube to a ${ }^{252} \mathrm{Cf}$ source in the high bay, a large testing facility located in Building 3440 at PNNL [Lintereur 2012]. This work reported that the model tended to agree closely with experiment when source-to-detector distances were closer than $0.5 \mathrm{~m}$, but the model tended to over-predict the detector response at distances greater than $1 \mathrm{~m}$. The experiment was replicated in the high bay, using the same source and one of the same tubes (Tube 1) as the earlier high bay experiment, in order to confirm the previous experimental measurements. Note that this is the same tube used for the high-statistics measurement described in Section 2.3.

The tube was oriented vertically in the center of a HDPE box with dimensions $10.6 \mathrm{~cm} \mathrm{x} 10.6 \mathrm{~cm}$ x $61 \mathrm{~cm}$. The ${ }^{252} \mathrm{Cf}$ was moderated by a cylindrical shield consisting of a lead pig $0.64 \mathrm{~cm}$ thick, surrounded by $2.54 \mathrm{~cm}$ of HDPE. The source was calculated to be $10.71 \mu \mathrm{Ci}$ (19.8 ng; 45620 $\mathrm{n} / \mathrm{s}$ ) on the first day of testing, June 25,2012 . The source center was placed on top of a tripod set to the height of the center of the ${ }^{10} \mathrm{~B}$-lined tube, $150 \mathrm{~cm}$ off the concrete floor, as shown in Figure 2.7. The source and detector were placed in the center of the room, as far from the walls as possible. The high voltage on the detector was set to $760 \mathrm{~V}$, in accordance with the manufacturer's specifications and Section 2.1. A shaping time of $1 \mu \mathrm{s}$ was used for these measurements. The measurement time was varied for each source-detector distance, in order to get total count statistics within $2 \%$. 


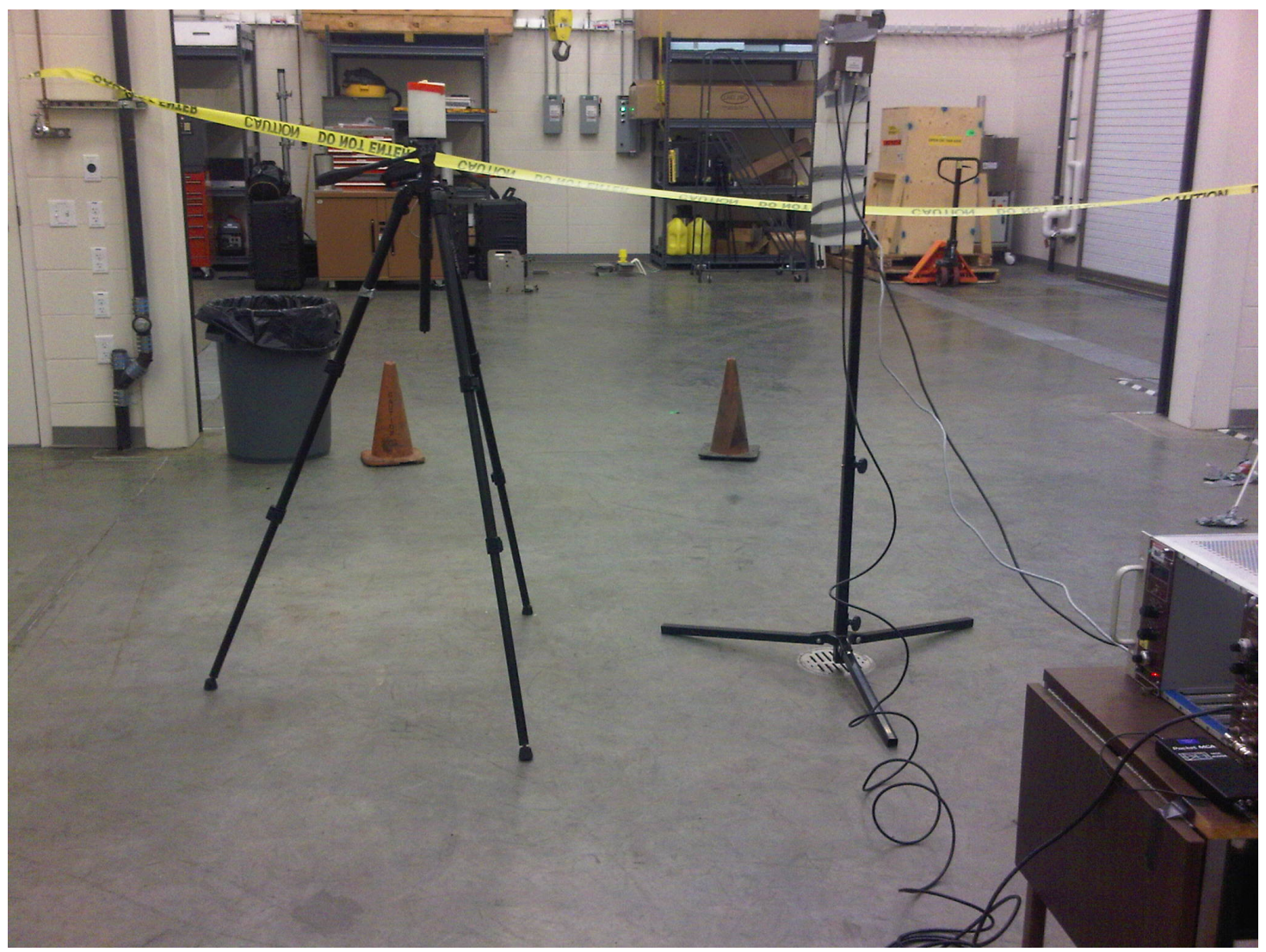

Figure 2.7. Moderated ${ }^{10} \mathrm{~B}$-lined tube (right) and moderated ${ }^{252} \mathrm{Cf}$ source on tripod (left).

The results of these measurements are shown for each measurement distance in Table 2.2. The net counts were determined from the data, and the count rate was determined per ng of source material. These results agree with the experimental data in Lintereur et al. [Lintereur 2012] within two standard deviations.

Table 2.2. Results of response of individual, moderated ${ }^{10} \mathrm{~B}$-lined tube to moderated ${ }^{252} \mathrm{Cf}$ source.

\begin{tabular}{|c|c|c|}
\hline Distance (m) & Count Time (s) & cps/ng \\
\hline 0.1 & 1800 & $4.53 \pm 0.01$ \\
\hline 0.25 & 1800 & $1.81 \pm 0.01$ \\
\hline 0.5 & 1800 & $0.647 \pm 0.005$ \\
\hline 1 & 3600 & $0.218 \pm 0.002$ \\
\hline 2 & 10800 & $0.065 \pm 0.001$ \\
\hline
\end{tabular}




\section{Model for Single-tube Comparison}

The experimental setup described in Section 2.3 was modeled in the Extended, Monte Carlo NParticle code (MCNPX) version 2.7.0 [Pelowitz 2011]. Previous modeling studies at PNNL guided this work [Lintereur 2012; Siciliano 2012].

The ${ }^{3} \mathrm{He}$ and ${ }^{10} \mathrm{~B}$-lined tube models occupied a small area of the laboratory model space shown in Figure 3.1, representing part of Room 1304 of Building 3420 at PNNL. The moderator arrangement is pictured as the group of solid objects near the center of Figure 2.3. The laboratory environment included several objects that could have had small impacts on the measurement, including the floor, walls, ceiling, and nearby items such as tables and NIM bin components. A stack of ${ }^{3} \mathrm{He}$ tubes that were removed from the polyethylene moderator arrangement before the measurement was lying on the nearby table; these were modeled, but are not pictured in Figure 3.1. The building's exterior wall was located less than two meters from the moderator assembly. This wall was modeled as a concrete wall $15-\mathrm{cm}$ thick, and appears as the purple wall on the right side of Figure 3.1.

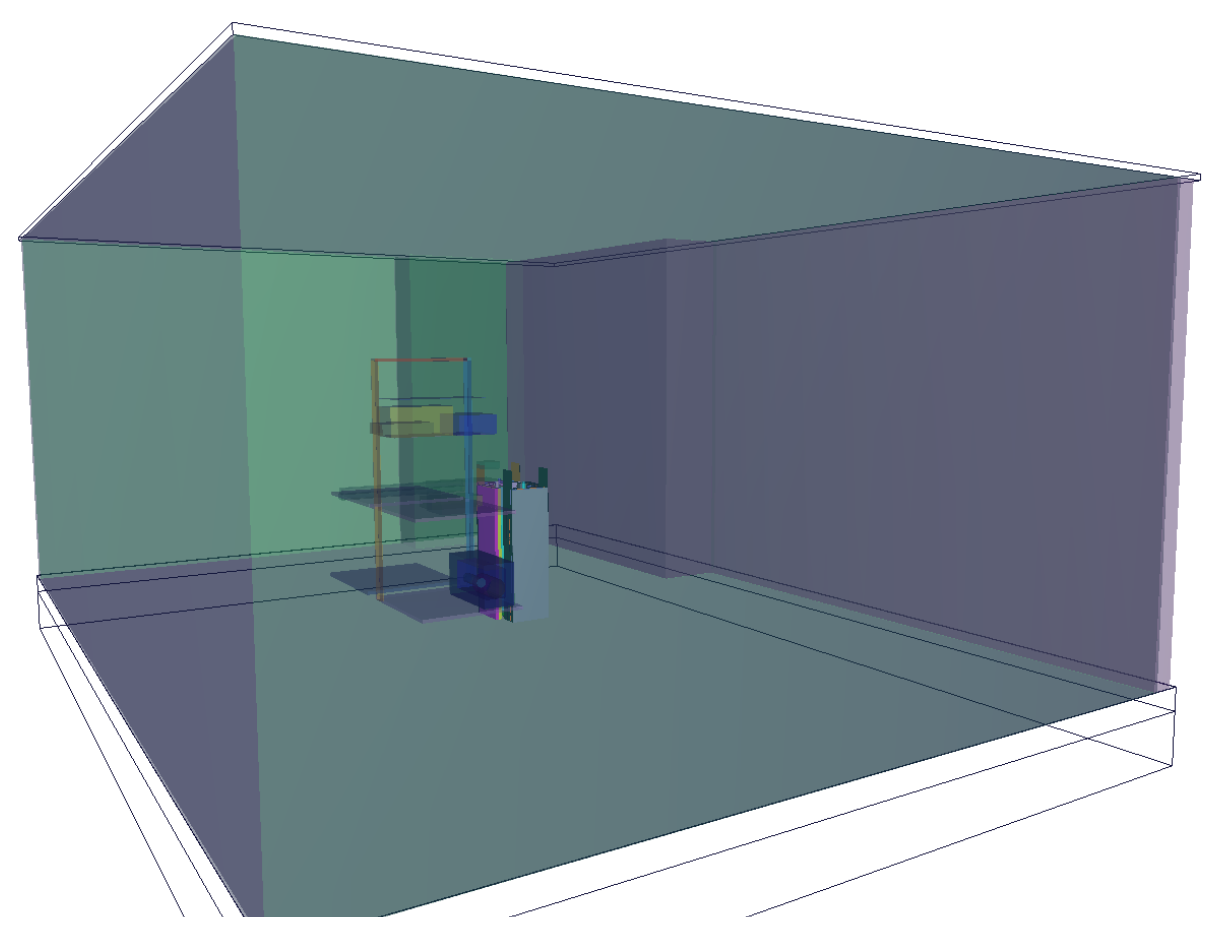

Figure 3.1. 3-D view of lab model.

Top-down and side views of the moderator assembly are shown in Figure 3.2 and Figure 3.3, respectively. The moderator assembly, as described in Section 2.3, consisted of four banks of high density polyethylene (HDPE) blocks. Each of the four banks consisted of four HDPE blocks. Nearest the source were two $5.08-\mathrm{cm}$ thick, $30.8-\mathrm{cm}$ wide, $101.4-\mathrm{cm}$ tall blocks with three $5.08-\mathrm{cm}$ (2-inch) diameter holes for the detection tubes. Behind the slotted blocks were two 
2.54-cm (1-inch) thick, 30.8-cm wide, 101.4-cm tall blocks to reflect neutrons back into the detection tubes.

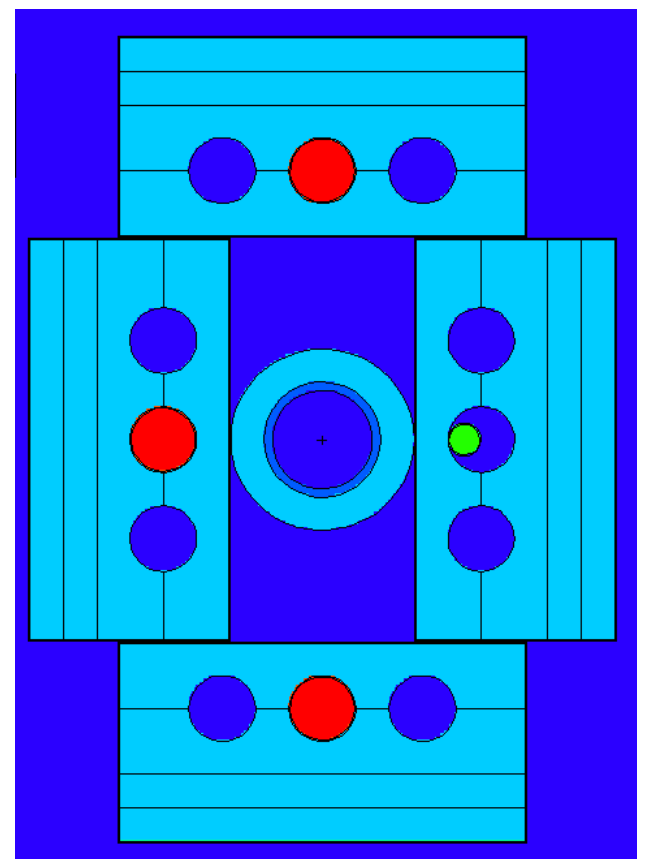

Figure 3.2. Top down view of the moderator arrangement $\left[{ }^{3} \mathrm{He}\right.$ tube is red, ${ }^{10} \mathrm{~B}$-lined tube is green].

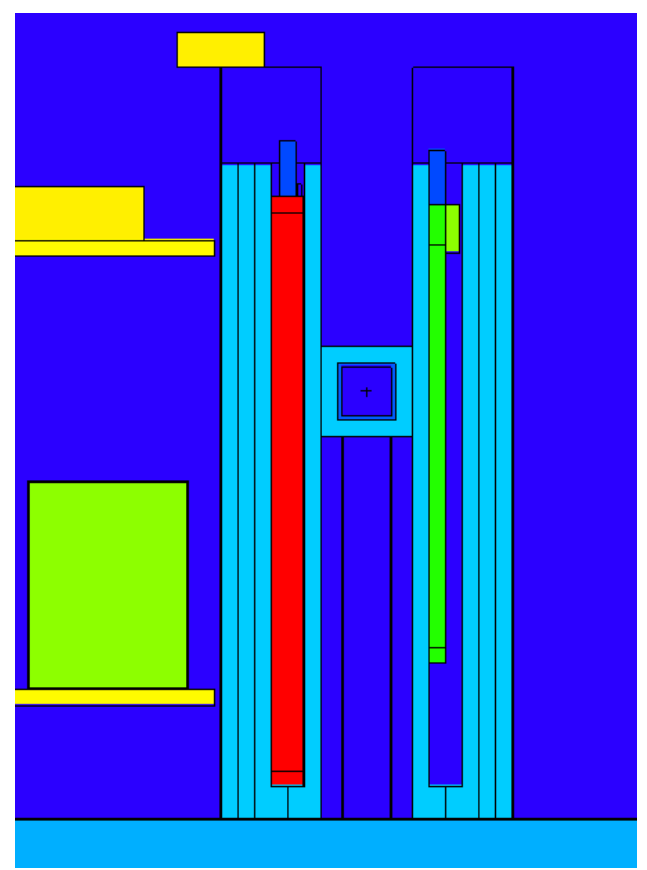

Figure 3.3. Side view of the moderator arrangement, including the source (center) and several nearby objects.

The source holder consisted of three concentric cylinders. The smallest was the air-filled source compartment 7.62-cm (3-inches) in diameter and 7.62-cm (3-inches) high. The next was a 0.635 - 
$\mathrm{cm}$ thick lead liner to attenuate the photons produced by the ${ }^{252} \mathrm{Cf}$ source. The outer layer was a 2.54-cm (1-inch) thick HDPE cylinder that moderated the ${ }^{252} \mathrm{Cf}$ source neutrons. The source itself was modeled as an air cylinder, neglecting the shielding effect of the source itself. The source sat on top of a $0.3-\mathrm{cm}$ thick cardboard poster tube cut to 59.2-cm in length, which allowed the source to be nearly vertically centered on the ${ }^{10} \mathrm{~B}$-lined tube.

Typical production runs used $5 \times 10^{7}$ neutron histories emitted from the source and tallied in both detectors. The boron in the lining was enriched to $\sim 92 \%$ to match the values from GE [GE Reuter-Stokes 2005]. The ${ }^{10} \mathrm{~B}$-lined tubes were filled with approximately 0.3 atmospheres of $90 \%$ argon, $10 \%$ carbon dioxide gas. The ${ }^{3} \mathrm{He}$ tubes were filled to a pressure of 4 atmospheres.

\subsection{Model Evaluation Methods}

While the total count response of ${ }^{3} \mathrm{He}$ tubes can be modeled to within a few percent of experimental values with simple capture tallies, modeling ${ }^{10} \mathrm{~B}$-lined tubes requires a more involved approach. Since the particles that are produced in the boron lining may not escape into the gas, the simple capture tally can produce large overestimates of the signal produced in an actual ${ }^{10} \mathrm{~B}$-lined tube. Modeling the total count response of ${ }^{10} \mathrm{~B}$-lined detectors thus requires tracking the ${ }^{7} \mathrm{Li}$ and ${ }^{4} \mathrm{He}$ reaction products and their interactions in the gas.

Accurate tracking of the reaction products requires that the particles are constrained to be emitted in anti-correlation. The physics options needed to ensure anti-correlation and reaction product tracking are included in the Neutron Capture Ion Algorithm (NCIA) available in MCNPX 2.7.0. Using the neutron physics option that implements the NCIA, whether or not the cross section data file includes data for the final state particles, is recommended. If data for one reaction ion is present in the cross section library and the proper NCIA option ( $\mathrm{recl}=5)$ is not selected, the particles will not be constrained to be emitted in opposite directions [Lintereur 2012; Pelowitz $2011]$.

As with any model, some approximations are necessary in the geometry or material composition of several system components. While GE Reuter-Stokes provides most of the parameters of both the ${ }^{3} \mathrm{He}$ and ${ }^{10} \mathrm{~B}$-lined tubes, some, including the thickness and composition of the boron lining, are withheld as proprietary to the vendor. The lining thickness and composition are thus variable parameters in this model. Previous work at PNNL has suggested that a $0.75 \mu \mathrm{m}$ thick boronmetal layer most accurately models the total count rate characteristics of the detector when compared to experiments, however that model for the lining did not describe the preliminary pulse height shapes [Lintereur 2012].

Several MCNP tally methods can be used to simulate the proportional gas response to the reaction ions produced by the neutron capture reactions in the boron lining [Siciliano 2010; Lintereur 2012]. For the ${ }^{10} \mathrm{~B}$-lined tubes, F8 tallies for the ${ }^{4} \mathrm{He}$ and ${ }^{7} \mathrm{Li}$ products may be used to display the energy distribution of the pulses created in the proportional gas, while the F6 energy deposition tally may be used to model the total energy deposited in the proportional gas. Additionally, the two tallies may be combined using the pulse-height light (PHL) treatment. The PHL treatment involves converting the energy deposition from the F6 tally into an equivalent amount of light, which can be registered by the F8 tally [Pelowitz 2011]. When used correctly, 
all three tallies should confirm the same result for the same parameter (i.e., total count efficiency).

The PHL treatment can also produce a pulse-height spectrum for modeled ${ }^{3} \mathrm{He}$ detectors, which provides an additional check on the capture tally results. Standard F8 tallies are not appropriate for ${ }^{3} \mathrm{He}$ proportional counters because $\mathrm{F} 8$ tallies do not produce reliable spectra when the particles are produced in the same media that ultimately generates the detection signal. The standard F8 tally scores the difference in energy between when a particle enters a material and when it is no longer available for tracking (either because it escaped the cell or was captured while in the cell). If the particle is created in the cell in which the signal is generated, and doesn't technically "enter" the cell, the F8 tally results will not be accurate. In the ${ }^{10} \mathrm{~B}$-lined case, the charged particles must travel from the lining to the gas to deposit their energy, so the net energy deposition in the cell representing the active region is calculated based on the energy of the products entering the cell, and the detector response can be modeled with the F8 tally. Only the PHL treatment provides a method for simulating a pulse-height spectrum in models of ${ }^{3} \mathrm{He}$ detectors [Pelowitz 2011].

The Gaussian Energy Broadening (GEB) feature was used for the F8-type tallies to more accurately simulate the loss of ideal resolution (blurring) that occurs in a physical detector. The GEB treatment does not alter the kinetic energy position or change the total count area of the peak; it simply distorts spectral features based on FWHM. Its effect on these simulations is to smooth the fall-off of the maximum kinetic-energy regions of the ${ }^{7} \mathrm{Li}$ and ${ }^{4} \mathrm{He}$ particles in the simulated ${ }^{10} \mathrm{~B}$-lined pulse-height spectra to more accurately approximate the wall effect, and to broaden the pulse-height spectrum of the full-energy peak and the charged particle continuum in the simulated ${ }^{3} \mathrm{He}$ PHL spectrum. The GEB parameters are specified by the user to set the fullwidth at half-maximum (FWHM) of the observed energy broadening in a physical radiation detector, according to the formula $F W H M=a+b \sqrt{E+c E^{2}}$, where $\mathrm{E}$ is the energy of the particle, and a, b, and c are the parameters input by the user [Pelowitz 2011].

\subsection{Model Results}

The total count efficiency of the modeled ${ }^{3} \mathrm{He}$ tube was calculated using the F4 capture tally to be $3.48 \%$, an overestimate of $0.45 \%$ compared to experiment. Slight overestimates are expected in models because physical systems experience small losses in signal in the detector electronics. The model's PHL spectrum is compared with the measured pulse height spectrum in Figure 3.4. While the spectra have notably different shapes, the area under their curves agrees within $1 \%$ (see Table 3.1). The difference in shapes is because the PHL tally treatment uses the GEB treatment to model a Gaussian fit to the data, while the measured spectrum does not have a Gaussian shape. The GEB parameters used for the model PHL spectrum were selected by measuring the full width at half maximum (FWHM) of the measured peak (53 keV), and varying the GEB parameters to match this FWHM within $2 \mathrm{keV}$. The GEB parameters $(\mathrm{a}, \mathrm{b}, \mathrm{c})$ used in Figure 3.4 were $0,0.06$, and 0 , respectively, which sets the FWHM of the model full-energy peak to $55 \mathrm{keV}$. These GEB values represent a compromise between the various non-Gaussian features in the measured spectrum. 
Table 3.1. Percent difference between model and measurements for individual ${ }^{3} \mathrm{He}$ tube.

\begin{tabular}{||c|c|c|c||}
\hline Detector & $\begin{array}{c}\text { Measurement } \\
\boldsymbol{\varepsilon}\end{array}$ & $\begin{array}{c}\text { Model } \\
\boldsymbol{\varepsilon}\end{array}$ & $\begin{array}{c}\boldsymbol{\varepsilon} \\
\text { Percent Difference }\end{array}$ \\
\hline He-3 & $3.47 \%$ & $3.48 \%$ & $0.45 \%$ \\
\hline
\end{tabular}

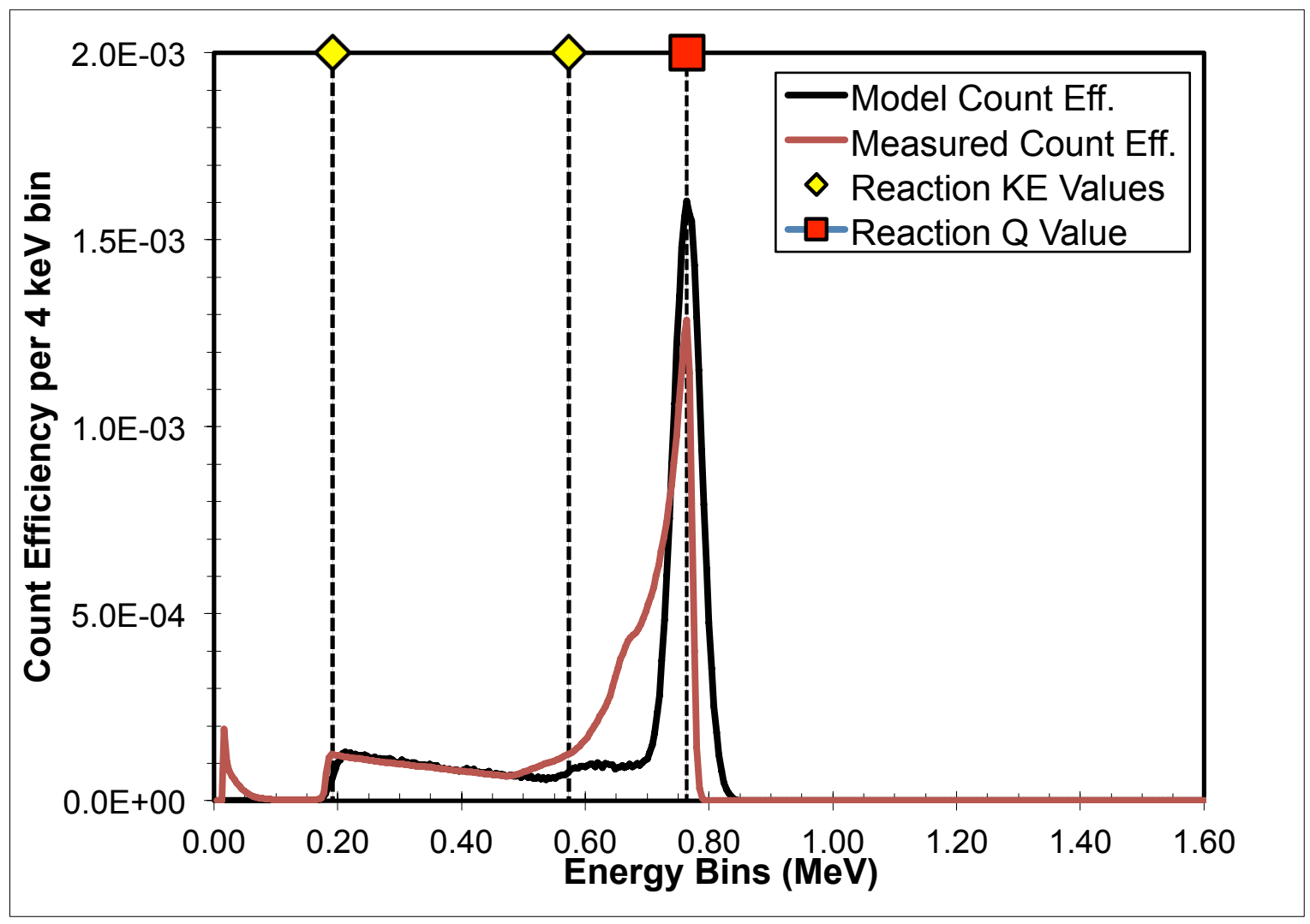

Figure 3.4. Pulse-height light spectrum for modeled ${ }^{3}$ He tube.

The percent differences between the model and measurement count efficiency values of various boron linings with various boron lining thicknesses and compositions are shown in Table 3.2. The closest agreement between model and experiment was the $0.75 \mu \mathrm{m} \mathrm{B}$ metal lining with no LEC, or the $2.5 \mu \mathrm{m} \mathrm{B}{ }_{4} \mathrm{C}$ lining with a $100 \mathrm{keV}$ LEC. Since the experimental measurement threshold was set at $\sim 21 \mathrm{keV}$, the $0.75 \mu \mathrm{m}$ boron lining shows the closest agreement with measurement results (within 3\% when LEC is considered). This also agrees with previous singletube modeling work at PNNL, using a different geometrical arrangement [Lintereur 2012]. 
Table 3.2. Percent differences between model and measurements for individual ${ }^{10} \mathrm{~B}$-lined tubes.

\begin{tabular}{|c|c|c|c|}
\hline $\begin{array}{l}\text { Tube } \\
\text { Lining }\end{array}$ & $\begin{array}{c}\text { Lining Thickness } \\
(\mu \mathrm{m})\end{array}$ & $\begin{array}{c}\text { LEC } \\
(\mathrm{keV})\end{array}$ & $\begin{array}{c}\varepsilon \\
\text { Percent Difference }\end{array}$ \\
\hline \multirow{14}{*}{$\begin{array}{c}\text { B } \\
\text { Metal }\end{array}$} & \multirow{2}{*}{0.75} & 0 & $-0.63 \%$ \\
\hline & & 100 & $-8.20 \%$ \\
\hline & \multirow{2}{*}{1.0} & 0 & $12.22 \%$ \\
\hline & & 100 & $3.89 \%$ \\
\hline & \multirow{2}{*}{1.5} & 0 & $21.76 \%$ \\
\hline & & 100 & $11.70 \%$ \\
\hline & \multirow{2}{*}{2.0} & 0 & $23.01 \%$ \\
\hline & & 100 & $13.35 \%$ \\
\hline & \multirow{2}{*}{2.5} & 0 & $22.61 \%$ \\
\hline & & 100 & $12.46 \%$ \\
\hline & \multirow{2}{*}{3.0} & 0 & $20.06 \%$ \\
\hline & & 100 & $8.41 \%$ \\
\hline & \multirow{2}{*}{3.5} & 0 & $15.96 \%$ \\
\hline & & 100 & $2.27 \%$ \\
\hline \multirow{2}{*}{$\mathrm{B}_{4} \mathrm{C}$} & \multirow{2}{*}{2.5} & 0 & $11.68 \%$ \\
\hline & & 100 & $-0.11 \%$ \\
\hline \multirow{2}{*}{$\mathrm{BN}$} & \multirow{2}{*}{2.5} & 0 & $-16.45 \%$ \\
\hline & & 100 & $-34.83 \%$ \\
\hline
\end{tabular}

The comparison of the measured ${ }^{10} \mathrm{~B}$-lined pulse height spectrum with model spectra produced using $0.75 \mu \mathrm{m}{ }^{10} \mathrm{~B}$ metal, $3.0 \mu \mathrm{m}{ }^{10} \mathrm{~B}$ metal, and $2.5 \mu \mathrm{m} \mathrm{B}{ }_{4} \mathrm{C}$, is shown in Figure 3.5. The vertical dashed lines show the energy end points for the various particle contributions. For the ${ }^{10} \mathrm{~B}$-lined tube models, the GEB parameters $(\mathrm{a}, \mathrm{b}, \mathrm{c})$ were $0,0.15$, and 0 , respectively, following previous modeling work at PNNL [Lintereur 2012].

While the measured spectrum shows a double-plateau shape, the model spectrum for the $0.75 \mu \mathrm{m}$ ${ }^{10} \mathrm{~B}$ shows a double-hump shape. The slightly longer energy distribution for the Li particle and the formation of a peak for the alpha particle's energy deposition are both possible indicators that the boron lining is likely thicker or composed of different materials. The $3.0 \mu \mathrm{m}{ }^{10} \mathrm{~B}$ metal and $2.5 \mu \mathrm{m} \mathrm{B}_{4} \mathrm{C}$ linings show better agreement with measured pulse height spectrum for the alpha drop-off. The transition region between the $\mathrm{Li}$ and alpha particles does not agree as closely in the thicker linings as in the $0.75 \mu \mathrm{m}$ lining. The $0.75 \mu \mathrm{m}{ }^{10} \mathrm{~B}$ metal lining is used as the model basis throughout this work because of its agreement with the total count statistics in the measured ${ }^{10} \mathrm{~B}$ lined tube. 


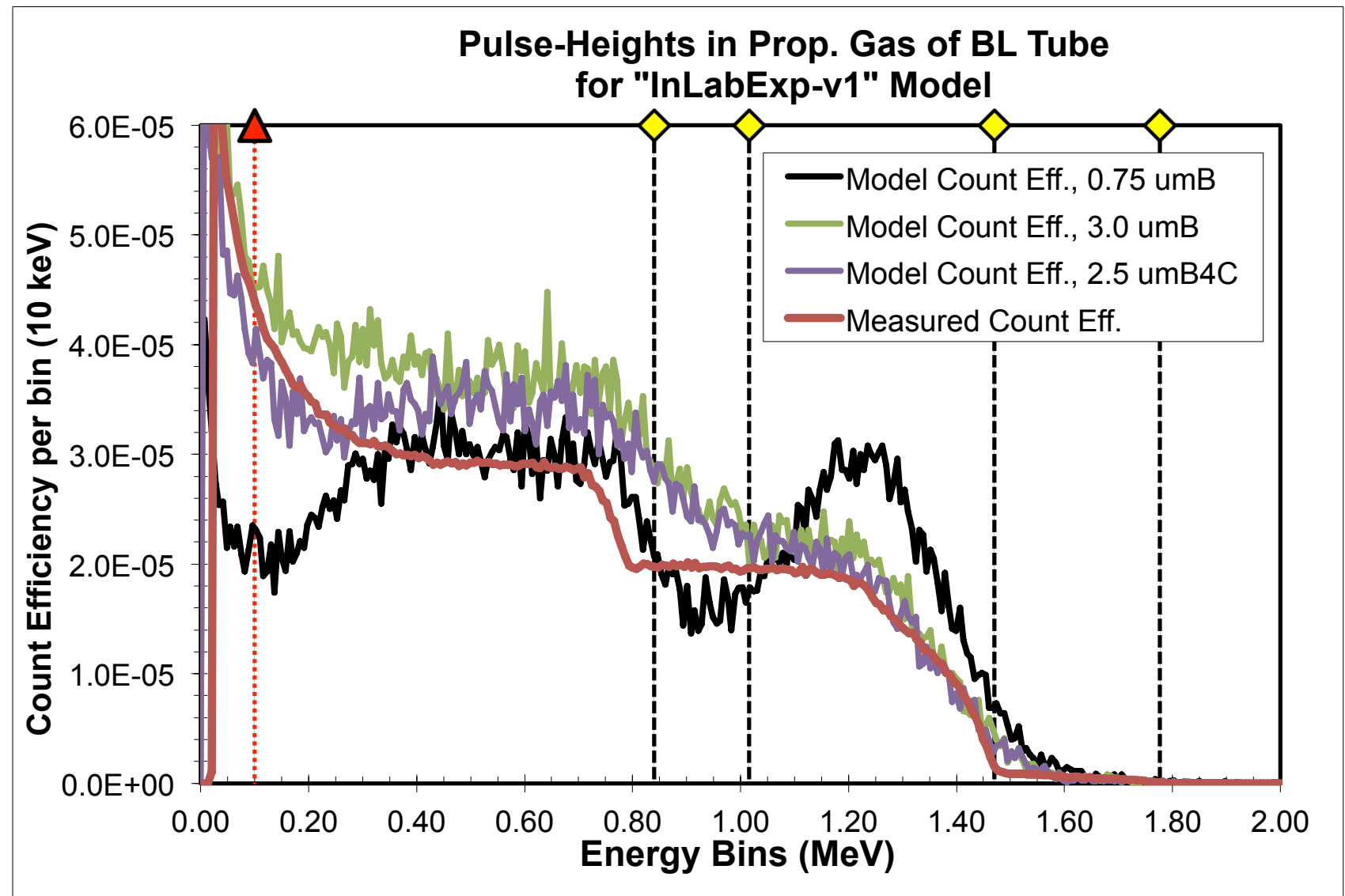

Figure 3.5. Comparison of measured pulse height spectra for ${ }^{10} \mathrm{~B}$-lined proportional counter with model pulse height spectra using various ${ }^{10} \mathrm{~B}$ lining thicknesses and compositions.

As seen in Figure 3.6, the thickness of the boron lining has a significant effect on several performance measures. The capture efficiency of the lining increases with increasing lining thickness, with the rate of increase gradually diminishing as the lining is made thicker. However, the detector's total count efficiency reaches a peak between 1.5 and $2.5 \mu \mathrm{m}$ as more reaction products deposit their kinetic energy in the lining before they can reach the proportional gas. The die-away time is a measure of the time it takes for neutrons in the system to be terminated by being counted, by being stopped but not counted, or by escaping the system [Siciliano 2012b]. The die-away time is an important parameter for coincidence counters, which will be discussed in greater detail in the forthcoming report on alternative counters. The die-away time falls away exponentially as the lining thickness increases and more neutrons are captured. All three of these parameters are important in the design of ${ }^{10} \mathrm{~B}$-lined systems, especially those using multiple ${ }^{10} \mathrm{~B}$ lined tubes [Ely 2011]. 


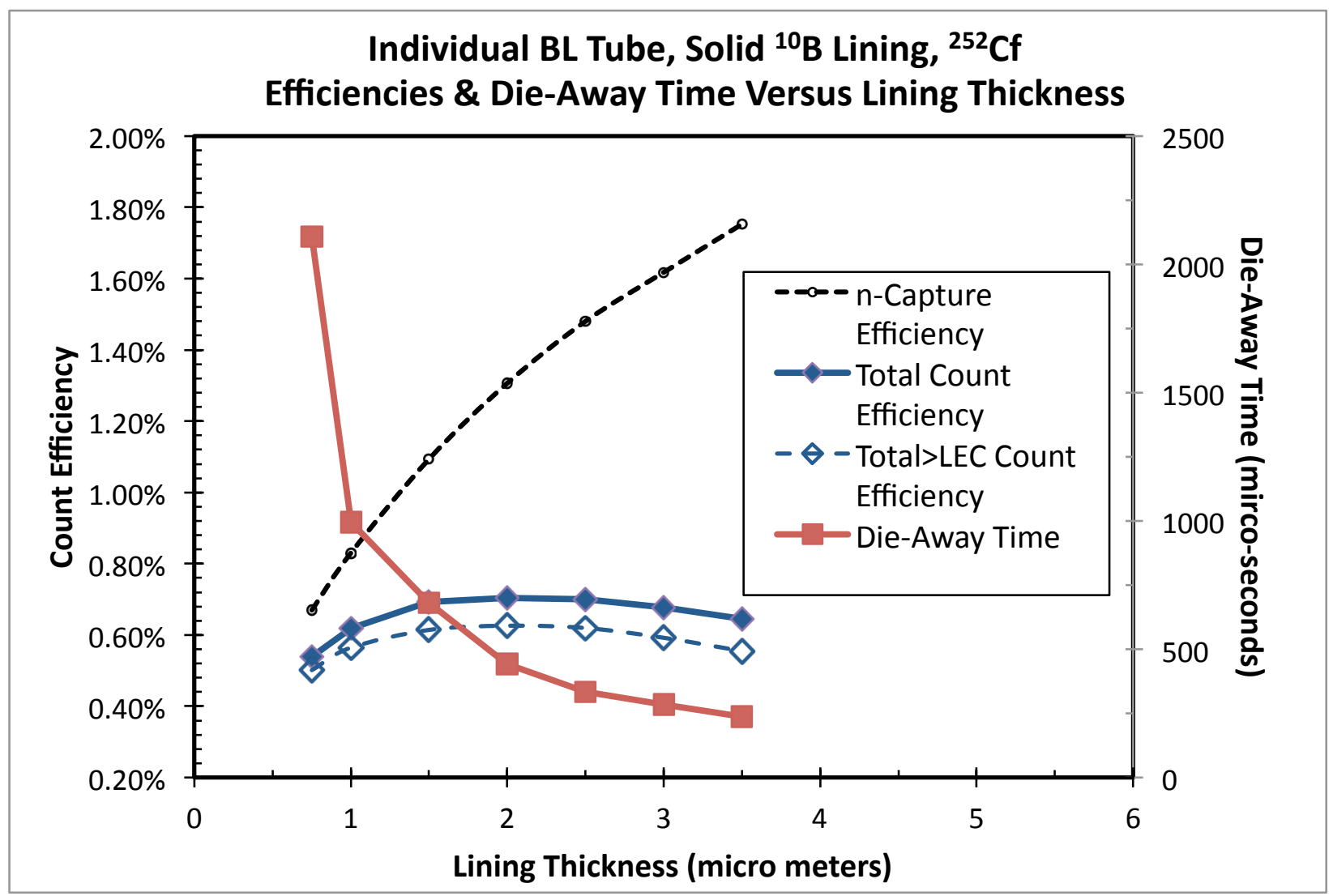

Figure 3.6. Effect of boron lining thickness on n-capture reactions, count efficiency, and die-away time in individual ${ }^{10} \mathrm{~B}$-lined detector system. 


\section{Conclusions}

This report includes several aspects of the effort to develop MCNPX models for boron-based UNCL coincidence counters for applications in safeguards for Task 2 of the project Coincidence Counting With Boron-Based Alternative Neutron Detection Technology. This report provides results of various studies related to this project performed by a summer intern supported by the Next Generation Safeguards Initiative.

The measured response of a ${ }^{10} \mathrm{~B}$-lined proportional counter to a ${ }^{252} \mathrm{Cf}$ source was compared directly to the measured response of a ${ }^{3} \mathrm{He}$ proportional counter in a close, symmetrical geometry. The ${ }^{3} \mathrm{He}$ tube measured was longer and larger in diameter than the ${ }^{10} \mathrm{~B}$-lined tube. Using total count efficiency as the measure of comparison, the efficiencies of the ${ }^{3} \mathrm{He}$ counter to the ${ }^{10} \mathrm{~B}$-lined tube were determined to be $6.39: 1$.

The measurement geometry where both detectors were close to the source in a symmetrical arrangement was modeled in MCNPX in order to validate the model geometry. The model for the ${ }^{3} \mathrm{He}$ tube agreed within $1 \%$ with the measured efficiency values, and the ${ }^{10} \mathrm{~B}$-lined tube using a boron-metal lining $0.75 \mu \mathrm{m}$ thick agreed within $10 \%$ with the measured efficiency values.

Boron-10-lined tubes with $0.75-\mu \mathrm{m}$ boron-metal lining are used as the basis for the direct replacement of the ${ }^{3} \mathrm{He}$ tubes in models of UNCL coincidence counters. These Alternative Boron-based UNCL (ABUNCL) models will be discussed in a separate report. 


\section{Acknowledgements and Support}

The United States Department of Energy Office of Nuclear Safeguards and Security (NA-241) supported this work. Pacific Northwest National Laboratory is operated for the United States Department of Energy under contract DE-AC05-76RLO 1830. Azaree Lintereur is a postMasters Research Assistant supported at Pacific Northwest National Laboratory by the Next Generation Safeguards Initiative, Office of Nuclear Safeguards and Security, National Nuclear Security Administration. Jeremy Rogers is a Masters Intern supported at Pacific Northwest Laboratory by the Next Generation Safeguards Initiative, Office of Nuclear Safeguards and Security, National Nuclear Security Administration. 


\section{References}

Croft S, A Favalli, MT Swinhoe, CD Rael. 2011. State Of The Art Monte Carlo Modeling Of Active Collar Measurements And Comparison With Experiment. Los Alamos National Laboratory. INMM Conference Record 2011.

Ely JH, ER Siciliano, MT Swinhoe. 2011. Alternatives to Helium-3 for Neutron Multiplicity Detectors. Technical Report PNNL-SA-77627, Pacific Northwest National Laboratory, Richland, Washington. 52nd INMM Meeting, Palm Desert, CA, 17-21 July 2011.

GE Reuter-Stokes. 2005. Boron-10 Proportional Counter Fact Sheet. GEA-13542A. Twinsburg, $\mathrm{OH}$.

Knoll, GF. 2000. Radiation Detection and Measurement. John Wiley \& Sons.

Kouzes RT, JH Ely, AT Lintereur, and ER Siciliano. 2012. Introduction to Neutron Coincidence Counter Design Based on Boron-10. Technical Report PNNL-21090. Pacific Northwest National Laboratory, Richland, WA.

Kouzes RT, JH Ely, LE Erikson, WJ Kernan, AT Lintereur, ER Siciliano, DL Stephens, DC Stromswold, RM Van Ginhoven, and ML Woodring. 2010. "Neutron detection alternatives to for ${ }^{3}$ He homeland security." Nuclear Instruments and Methods in Physics Research A, 623(3):10351045 .

Lintereur AT, ER Siciliano, and RT Kouzes. 2012. Boron-10 Lined Proportional Counter Model Validation. Technical Report PNNL-21501. Pacific Northwest National Laboratory, Richland, WA.

ORTEC. 2010. Model 673 Spectroscopy Amplifier and Gated Integrater. Accessed at www.ortec-online.com.

PANDA. 1991. Passive Nondestructive Assay of Nuclear Materials (PANDA), Nuclear Regulatory Commission NRC-FIN-A7241. Los Alamos National Laboratory Report LA-UR-90732. Available at http://www.lanl.gov/orgs/n/n1/panda/index.shtml.

Pelowitz DB (ed.). 2011. "MCNPX User's Manual”, Version 2.7.0. Los Alamos National Laboratory Report LA-CP-11-00438.

Menlove HO. 1981. Description and Performance Characteristics for the Neutron Coincidence Collar for the Verification of Reactor Fuel Assemblies, Los Alamos National Laboratory Report LA-8939-MS.

Menlove HO. 1987. Neutron Collar Calibration for Assay of LWR Fuel Assemblies, Los Alamos National Laboratory Report LA-10827-MS.

Menlove HO, JE Stewart, SZ Qiao,TR Wenz, PD Verrecchia. 1990. Neutron Collar Calibration and Evaluation for Assay of L WR Fuel Assemblies Containing Burnable Neutron Absorbers, Los Alamos National Laboratory Report LA-11965-MS.

Menlove HO, D Henzlova, LG Evans, MT Swinhoe, and JB Marlow. 2011. ${ }^{3}$ He Replacement for Nuclear Safeguards Applications - an Integrated Test Program to Compare Alternative Neutron Detectors. ESARDA Bulletin 46.

Siciliano ER, JH Ely, RT Kouzes, ML Woodring. 2010. Simulating Boron-Based Detectors with MCNPX. Technical Report PNNL-SA-71579, Pacific Northwest National Laboratory, Richland, 
Washington.

Siciliano ER, and RT Kouzes. 2012. Boron-10 Lined Proportional Counter Wall Effects. Technical Report PNNL-21368. Pacific Northwest National Laboratory, Richland, WA.

Siciliano ER, JL Rogers, JE Schweppe, AT Lintereur, and RT Kouzes. 2012. Uranium Neutron Coincidence Collar Model Utilizing ${ }^{3}$ He. Technical Report PNNL-21581. Pacific Northwest National Laboratory, Richland, WA.

Switzer T, RR Hansen, RT Kouzes, RJ Arthur, WK Pitts. 2003. Neutron Detection Authentication Case Study: Revised Edition. Technical Report PNNL-14222. Pacific Northwest National Laboratory, Richland, WA. 


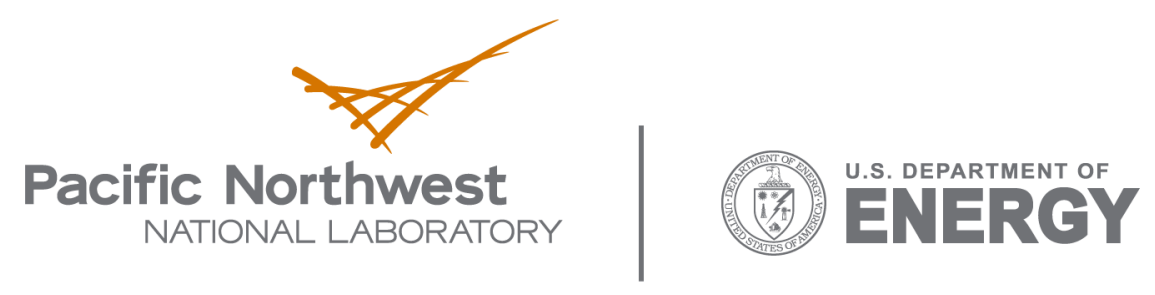

902 Battelle Boulevard

P.O. Box 999

Richland, WA 99352

1-888-375-PNNL (7665)

www.pnl.gov 